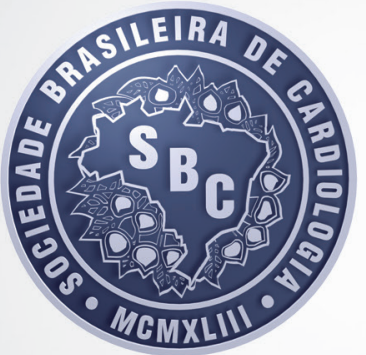

www.cardiol.br

Arquivos Brasileiros de

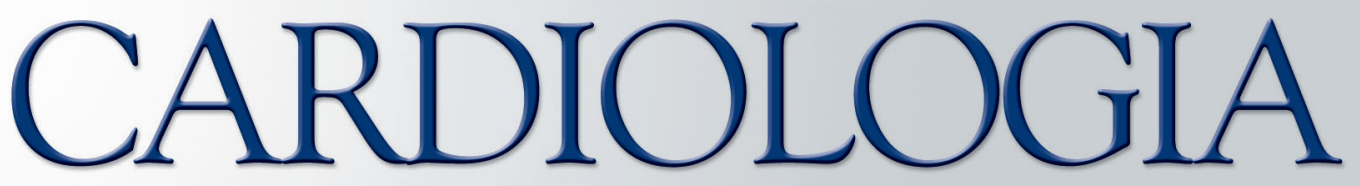

SOCIEDADE BRASILEIRA DE CARDIOLOGIA ISSN-0066-782X

Volume 96, $\mathbf{N}^{\circ}$ 5, Supl.1, Maio 2011

\title{
I DIRETRIZ DA SOCIEDADE BRASILEIRA DE CARDIOLOGIA SOBRE PROCESSOS E COMPETÊNCIAS PARA A FORMAÇÃO EM CARDIOLOGIA NO BRASIL
}




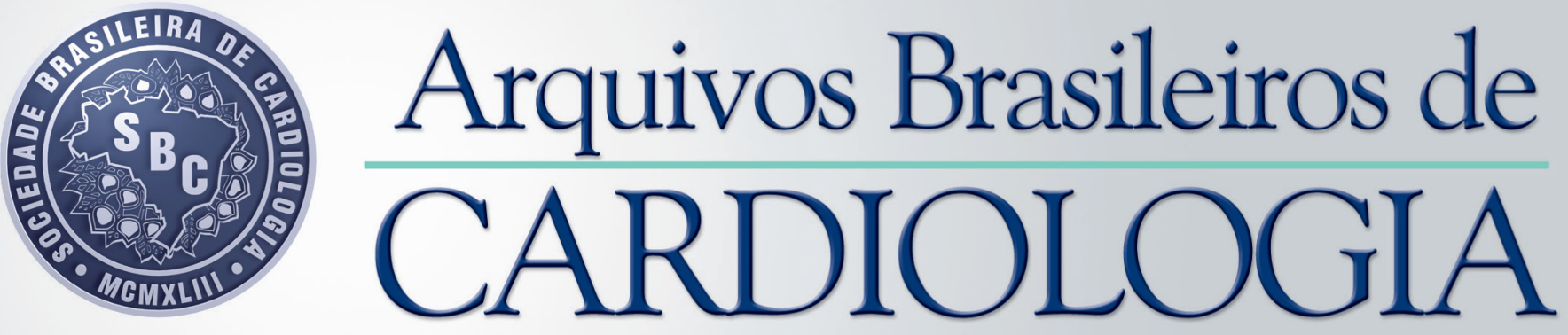

\section{DIRETRIZ DA SOCIEDADE BRASILEIRA DE CARDIOLOGIA SOBRE PROCESSOS E COMPETÊNCIAS PARA A FORMAÇÃO EM CARDIOLOGIA NO BRASIL}





\section{SUMÁRIO}

Introdução

página 4

Processo de formação, centros de treinamento e programas

página 4

Programação básica

página 4

Pré-requisito

página 4

Cardiologia

Corpo docente

Centros de treinamento

página 4

página 5

página 5

Conteúdo programático do currículo em cardiologia

página 5

1. Ética

página 5

2. Anamnese

3. Exame clínico

página 6

4. Exames complementares

página 6

4.1. Eletrocardiografia, Holter, teste de esforço

página 7

4.1.1. Eletrocardiograma

página 7

4.1.2. Holter ou eletrocardiografia ambulatorial de $24 \mathrm{~h}$

página 7

página 7

4.1.3. Teste de esforço e teste cardiopulmonar de exercício

página 7

4.2. Exames de imagem não invasivos: radiografia de tórax, ecocardiograma,

RNM, TC cardíaca e cardiologia nuclear

4.2.1. Ecocardiografia

página 8

4.2.2. Tomografia computadorizada cardíaca

página 8

4.2.3. Ressonância nuclear magnética (RNM) cardíaca

página 8

4.2.4. Cardiologia nuclear

4.3. Exames de imagem invasivos: cateterização e angiografia.

página 8

página 8

5. Prevenção e promoção em saúde

página 8

6. A interconsulta cardiológica

página 9

6.1. Consulta para avaliação pré-operatória para cirurgia não cardíaca

página 9

6.2. Interconsulta com a neurologia em pacientes com sintomas neurológicos isquêmicos ou acidente vascular encefálico

página 9

6.3. Interconsulta cardíaca com outras especialidades

7. Genética página 10

8. Farmacologia clínica

página 10

9. Hipertensão arterial sistêmica

página 11

10. Dislipidemia

página 11

página 11

11. Diabete melito

página 12

12. Tabagismo

13. Síndromes coronarianas agudas

página 12

página 13

14. Doença arterial coronariana crônica

página 13

15. Intervenção coronariana percutânea

16. Miocardiopatias

17. Cardiopatia Chagásica

18. Doença pericárdica

19. Tumores cardíacos 


\section{Diretrizes}

20. Doença cardíaca congênita

página 15

21. Cardiologia na mulher

página 15

22. Doença cardíaca valvar

23. Endocardite infecciosa

página 16

24. Febre reumática

25. Insuficiência cardíaca

página 17

página 17

26. Hipertensão arterial pulmonar

página 17

27. Reabilitação e fisiologia do exercício

página 18

28. Arritmias

página 18

29. Fibrilação atrial

página 19

30. Síncope

página 19

31. Morte súbita e ressucitação

32. Doenças da aorta e trauma da aorta e coração

página 20

33. Doença arterial periférica

página 20

página 20

34. Doença venosa tromboembólica

página 21

35. Doenças cardiovasculares no paciente idoso

página 21

36. Cirurgia

página 21

página 22

Referências página 23 


\section{Diretriz da Sociedade Brasileira de Cardiologia sobre Processos e Competências para a Formação em Cardiologia no Brasil}

\section{REALIZAÇ̃̃o}

Sociedade Brasileira de Cardiologia, com a participação dos

Departamentos Científicos e da Comissão Julgadora do Título de Especialista (CJTEC)

Coordenador de Normatizações e Diretrizes da SBC

Iran Castro

\section{Coordenadores Gerais e Editores}

Marcos Roberto de Sousa, Gilson Soares Feitosa

\section{Coeditores}

Jamil Cherem Schneider, Angelo Amato Vincenzo de Paola

Revisores

Gilson Soares Feitosa Filho, José Carlos Nicolau, João Fernando Monteiro Ferreira

\section{Grupo De Trabalho}

Regina Coeli Marques de Carvalho - Presidente do Departamento de Cardiologia da Mulher

William Azem Chalela - Presidente do Departamento de Ergometria, Exercício e Reabilitação Cardiovascular

Marcus Vinícius Bolívar Malachias - Presidente do Departamento de Hipertensão Arterial

José Luiz Barros Pena - Departamento de Imagem Cardiovascular

Frederico Somaio Neto - Departamento de Fisiologia Cardiovascular Respiratória e Cardiologia Experimental

Marcelo Westerlund Montera - Departamento de Cardiologia Clínica

Gilberto Venossi Barbosa - Sociedade Brasileira de Cirurgia Cardiovascular

Fernando Bacal - Departamento de Insuficiência Cardíaca

leda Biscegli Jatene - Departamento de Cardiologia Pediátrica

Raul D. Santos - Departamento de Aterosclerose

Roberto Dischinger Miranda - Departamento de Cardiogeriatria

José Maria Peixoto - Departamento de Cardiogeriatria

Mauricio de Rezende Barbosa - Presidente da Sociedade Brasileira de Hemodinâmica e Cardiologia Intervencionista

Guilherme Fenelon - Presidente-Sobrac

Jamil Cherem Schneider - Coordenador do TEC/SBC CJTEC I 2010 - 2011

Angelo Amato Vincenzo de Paola - Diretor Científico da SBC CJTEC I 2010 - 2011

Abdol Hakin Assef - Membro da CJTEC I 2010 - 2011

Alberto Francisco Piccolotto Naccarato - Membro da CJTEC I 2010 - 2011

Carlos Roberto Martins R Sobrinho - Membro da CJTEC I 2010 - 2011

Gilson Soares Feitosa Filho - Membro da CJTEC I 2010 - 2011 


\section{Diretrizes}

Ilmar Kohler - Membro da CJTEC I 2010 - 2011

José Narciso Gonçalves de Vasconcelos - Membro da CJTEC I 2010 - 2011

Marcos Jose Gomes Magalhães - Membro da CJTEC I 2010 - 2011

Marcos Roberto de Sousa - Membro da CJTEC I 2010 - 2011

Nelson Siqueira de Morais - Membro da CJTEC I 2010 - 2011

Ricardo Mourilhe Rocha - Membro da CJTEC I 2010 - 2011

Roberto Rocha Corrêa Veiga Giraldez - Membro da CJTEC I 2010 - 2011

Gláucia Cristina da Silva - Cardiologista do Hospital das Clínicas da UFMG

Esta diretriz deverá ser citada como:

de Sousa MR, Feitosa GS, de Paola AAV, Schneider JC, Feitosa-Filho GS, Nicolau JC, Ferreira JFM, et al. / SBC e CJTEC, Gláucia Cristina da Silva. I Diretriz da Sociedade Brasileira de Cardiologia sobre Processos e Competências para a Formação em Cardiologia no Brasil. Arq Bras Cardiol 2011; 96(5 supl.1): 1-24.

Correspondência:

Marcos R. de Sousa

Rua Aristides Duarte, 39 / 601 Prado - 30.410-040 - Belo Horizonte - Minas Gerais - Brasil

E-mail:mrsousa@cardiol.br 
Declaração obrigatória de conflito de interesses

Se nos últimos 3 anos o autor/colaborador das Diretrizes:

\begin{tabular}{|c|c|c|c|c|c|c|c|}
\hline $\begin{array}{l}\text { Nomes Integrantes } \\
\text { da Diretriz }\end{array}$ & $\begin{array}{l}\text { Participou de estudos } \\
\text { clínicos e/ou experimentais } \\
\text { subvencionados pela } \\
\text { indústria farmacêutica ou de } \\
\text { equipamentos relacionados à } \\
\text { diretriz em questão }\end{array}$ & $\begin{array}{l}\text { Foi palestrante em } \\
\text { eventos ou atividades } \\
\text { patrocinadas pela } \\
\text { indústria relacionados } \\
\text { à diretriz em questão }\end{array}$ & $\begin{array}{l}\text { Foi (é) membro } \\
\text { do conselho } \\
\text { consultivo } \\
\text { ou diretivo } \\
\text { da indústria } \\
\text { farmacêutica ou de } \\
\text { equipamentos } \\
\end{array}$ & $\begin{array}{l}\text { Participou } \\
\text { de comitês } \\
\text { normativos } \\
\text { de estudos } \\
\text { científicos } \\
\text { patrocinados pela } \\
\text { indústria }\end{array}$ & $\begin{array}{l}\text { Recebeu auxílio } \\
\text { pessoal ou } \\
\text { institucional da } \\
\text { indústria }\end{array}$ & $\begin{array}{l}\text { Elaborou textos } \\
\text { científicos em } \\
\text { periódicos } \\
\text { patrocinados pela } \\
\text { indústria }\end{array}$ & $\begin{array}{l}\text { Tem ações } \\
\text { da indústria }\end{array}$ \\
\hline \multicolumn{8}{|c|}{ Informar o nome da empresa em caso de resposta positiva } \\
\hline Abdol Hakin Assef & Não & Não & Não & Não & MSD, Sankyo & Não & Não \\
\hline $\begin{array}{l}\text { Alberto Francisco Piccolotto } \\
\text { Naccarato }\end{array}$ & Não & Não & Não & Não & Não & Não & Não \\
\hline $\begin{array}{l}\text { Angelo Amato Vincenzo } \\
\text { de Paola }\end{array}$ & Não & Não & Não & Não & Não & Não & Não \\
\hline $\begin{array}{l}\text { Carlos Roberto Martins R } \\
\text { Sobrinho }\end{array}$ & Não & Não & Não & Não & Não & Não & Não \\
\hline Fernando Bacal & Não & Não & Não & Não & Não & Não & Não \\
\hline Frederico Somaio Neto & Não & Não & Não & Não & Não & Não & Não \\
\hline Gilberto Venossi Barbosa & Não & Não & Não & Não & Não & Não & Não \\
\hline Gilson Soares Feitosa & Não & Não & Não & Não & Não & Não & Não \\
\hline Gilson Soares Feitosa Filho & Não & Não & Não & Não & Não & Não & Não \\
\hline Gláucia Cristina da Silva & Não & Não & Não & Não & Não & Não & Não \\
\hline Guilherme Fenelon & Não & Não & Não & Não & Não & Não & Não \\
\hline leda Biscegli Jatene & Não & Não & Não & Não & Não & Não & Não \\
\hline IImar Kohler & Não & Não & Não & Não & Boehringer Ingelheim & Não & Não \\
\hline Jamil Cherem Schneider & Não & Não & Não & Não & $\begin{array}{c}\text { Astra Zeneca, } \\
\text { Boheringher, } \\
\text { Novartis, MSD }\end{array}$ & Não & Não \\
\hline $\begin{array}{l}\text { João Fernando Monteiro } \\
\text { Ferreira }\end{array}$ & Não & Não & Baldacci & Não & MSD & Não & Não \\
\hline José Carlos Nicolau & Não & Não & Não & Não & Não & Não & Não \\
\hline José Luiz Barros Pena & Não & Não & Não & Não & Não & Não & Não \\
\hline José Maria Peixoto & Não & Não & Não & Não & Não & Não & Não \\
\hline $\begin{array}{l}\text { José Narciso Gonçalves de } \\
\text { Vasconcelos }\end{array}$ & Não & Não & Não & Não & Não & Não & Não \\
\hline Marcelo Westerlund Montera & Não & Não & Não & Não & Não & Não & Não \\
\hline $\begin{array}{l}\text { Marcos Jose Gomes } \\
\text { Magalhães }\end{array}$ & Não & Não & Não & Não & Não & Não & Não \\
\hline Marcos Roberto de Sousa & Não & Não & Não & Não & Não & Não & Não \\
\hline $\begin{array}{l}\text { Marcus Vinícius Bolivar } \\
\text { Malachias }\end{array}$ & Não & $\begin{array}{c}\text { AstraZeneca, } \\
\text { Novartis, BMS, MSD, } \\
\text { Boehringer-Ingelheim, } \\
\text { Servier }\end{array}$ & Não & Não & Não & $\begin{array}{c}\text { AstraZeneca, } \\
\text { Boehringer-Ingelheim, } \\
\text { Baldacci, Torrent, } \\
\text { Aché, BMS, } \\
\text { Bayer, Novartis }\end{array}$ & Não \\
\hline $\begin{array}{l}\text { Mauricio de Rezende } \\
\text { Barbosa }\end{array}$ & $\begin{array}{c}\text { CMS Medical, } \\
\text { Fahajanand Medical }\end{array}$ & Não & Não & Não & $\begin{array}{c}\text { Boston Scientific, } \\
\text { BBrun }\end{array}$ & Daichii Sankyo & Não \\
\hline Nelson Siqueira de Morais & Não & Não & Não & Não & Não & $\begin{array}{l}\text { Astra-Zeneca, } \\
\text { Sanofi-Aventis }\end{array}$ & Não \\
\hline Raul D. dos Santos & $\begin{array}{c}\text { Pfizer, } \\
\text { Astra Zeneca }\end{array}$ & $\begin{array}{c}\text { Pfizer, Astra Zeneca, } \\
\text { Biolab, MSD, Novartis, } \\
\text { Abbott, Lilly }\end{array}$ & $\begin{array}{c}\text { MSD, } \\
\text { Novo-Nordisk, GSK }\end{array}$ & $\begin{array}{c}\text { Pfizer, } \\
\text { ISIS-Genzyme }\end{array}$ & $\begin{array}{c}\text { Pfizer, } \\
\text { Astra Zeneca, MSD }\end{array}$ & $\begin{array}{l}\text { Pfizer, Astra Zeneca, } \\
\text { Biolab, Novartis, MSD }\end{array}$ & Não \\
\hline $\begin{array}{l}\text { Regina Coeli Marques de } \\
\text { Carvalho }\end{array}$ & Não & Não & Não & Não & Não & Não & Não \\
\hline Ricardo Mourilhe Rocha & Não & Não & Não & Não & Não & Não & Não \\
\hline Roberto Dischinger Miranda & Não & Não & Não & Não & $\begin{array}{l}\text { MSD, Novartis, } \\
\text { Libbs, Boehringer }\end{array}$ & $\begin{array}{c}\text { Pfizer, } \\
\text { MSD, Novartis }\end{array}$ & Não \\
\hline $\begin{array}{l}\text { Roberto Rocha Corrêa Veiga } \\
\text { Giraldez }\end{array}$ & Não & Não & Daiichi Sankyo & Não & $\begin{array}{l}\text { Novartis, MSD, } \\
\text { Daiichi Sankyo }\end{array}$ & $\begin{array}{l}\text { GSK, Daiichi Sankyo, } \\
\text { Novartis, Boheringer }\end{array}$ & Não \\
\hline William Azem Chalela & Não & Não & Não & Não & Não & Não & Não \\
\hline
\end{tabular}




\section{Introdução}

As doenças do aparelho circulatório apresentam prevalência, morbidade e letalidade elevadas, tornando especialmente relevante a definição de competências para a prática cardiológica.

Os avanços na metodologia científica, em várias situações, propiciaram redução da mortalidade, a exemplo de pacientes hospitalizados com infarto do miocárdio, de 15 a 20\%, na década de 80, para em torno de 7 a 5\%, nos tempos atuais. O rigor da aplicação metodológica tem demonstrado a complexidade da abordagem a ser empregada quando revela, por exemplo, que condutas baseadas na redução de desfechos substitutivos podem não reduzir, ou até aumentar, desfechos clínicos desfavoráveis.

Por outro lado, a Medicina incorpora a ciência e o método científico à arte de ser médico. Dessa forma, sem qualidades humanísticas, a aplicação da ciência moderna é subótima, ineficaz ou mesmo iatrogênica. No âmbito da Medicina - e da Cardiologia, em particular -, a ênfase do processo avaliativo deve centrar-se nas competências, indo, portanto, além dos conhecimentos. Competência em Medicina é o conhecimento, o discernimento de evidências, a habilidade técnica, o raciocínio clínico, das emoções, dos valores, o uso judicioso e habitual da comunicação, e a reflexão na prática diária para o benefício de indivíduos e da comunidade à qual ele serve. É um hábito de aprendizado constante ao longo da vida. Competência é contextual, reflete o relacionamento entre as habilidades da pessoa e as tarefas que ela precisa realizar em uma situação no mundo real. A competência, assim como a ética, começa no discurso do conhecimento teórico, concomitantemente ao desenvolvimento de habilidades, e termina na ação, por meio de comportamentos e atitudes.

\section{Processo de formação, centros de treinamento e programas}

A Comissão Mista de Especialidades (CME) foi criada pelo convênio celebrado em 11 de abril de 2002, entre o CFM, a $A M B$ e a CNRM, visando a estabelecer critérios para o reconhecimento e a denominação de especialidades médicas. A partir dessa data, o CFM, a AMB e a CNRM reconhecem as mesmas especialidades.

Atualmente, a Comissão Nacional de Residência Médica (CNRM) é responsável pelo credenciamento e fiscalização dos programas de residência, emitindo certificados de conclusão da residência médica devidamente reconhecidos pelo Conselho Federal de Medicina (CFM). Como alternativa, a Associação Médica Brasileira (AMB) concede o Título de Especialista em Cardiologia (TEC) por meio de concurso de provas e títulos realizado pela Sociedade Brasileira de Cardiologia (SBC), também com o reconhecimento do CFM, a candidatos que atendam requisitos básicos de formação cardiológica.

É importante ressaltar que cursos teóricos de PósGraduação lato sensu servem apenas para reciclar e podem ter outras finalidades, mas não são suficientes para formar cardiologistas, sendo tacitamente rejeitados também pelo CFM como formadores, em que pese a indefinição do MEC sobre o assunto.
Apesar dos enormes avanços no processo avaliativo para obtenção do título, e do profissionalismo da SBC no enfrentamento deste problema, ainda não foram unificados os processos de formação, persistindo ainda, atualmente, dois especialistas com formação muito diferente e títulos equivalentes. A Comissão de Julgamento de Títulos de Especialistas em Cardiologia (CJTEC-SBC) ampliou recentemente sua área de atuação e passou a fiscalizar e credenciar programas de especialização, estabelecendo quesitos mínimos.

Na SBC, a CJTEC é a comissão responsável por modelar e monitorar continuamente os programas de treinamento em Cardiologia, com o objetivo final de tornar a formação de cardiologistas no Brasil uniforme e com qualidade. Após discussões intensas na CJTEC, e no âmbito de duas plenárias no 65ํㅡㄹ Congresso da SBC, em Belo Horizonte, Minas Gerais, no ano de 2010, e após reunião com todos os Departamentos Científicos da SBC e com todos os membros da CJTEC, em 19/02/2011, decidiu-se, com unanimidade, que a SBC e a CJTEC definiriam quesitos mínimos para a formação em Cardiologia, respeitando os pré-requisitos necessários. No caso da Cardiologia, são necessários dois anos de formação em Clínica Médica precedendo o treinamento em Cardiologia.

A partir de 2015, só poderão fazer o concurso para a prova de Título de Especialista em Cardiologia os candidatos que tenham sido formados em programas credenciados pela SBC ou pela CNRM, além dos casos excepcionais que comprovarem experiência de pelo menos 12 anos de atuação em Cardiologia. Os programas credenciados pela SBC terão até 2015 para se adaptarem às novas regras, exigindo de seus candidatos $\mathrm{O}$ treinamento no pré-requisito. Para serem credenciados ou para renovarem seus credenciamentos, os programas deverão seguir as seguintes diretrizes, com a seguinte programação (observe-se que a utilização dos termos "sugere-se", ou "recomenda-se", indica atividades opcionais e, portanto, não obrigatórias):

\section{Programação básica}

\section{Pré-requisito}

Dois anos de treinamento em clínica médica ou medicina interna com carga horária de 2.880 horas por ano (60 horas semanais, 48 semanas). Poderá ser realizado concurso único para um programa de quatro anos (dois anos em Clínica Médica e dois anos em Cardiologia, desde que credenciado por ambas sociedades) ou concursos separados para o prérequisito e Cardiologia. Os candidatos ao treinamento em Cardiologia deverão comprovar formação no pré-requisito de Clínica Médica por meio de:

- Declaração de conclusão de residência médica credenciada pela CNRM ou especialização em centro credenciado pela Sociedade Brasileira de Clínica Médica; ou

- Título de especialista em clínica médica conferido pela $\mathrm{AMB}$.

\section{Cardiologia}

Duração mínima de 24 meses, carga horária de 2.880 horas por ano (60 horas semanais, 48 semanas), incluindo: 
A - O programa deverá ter no mínimo 10\% e no máximo $20 \%$ de sua carga horária exclusivamente para atividades teóricas: aulas, seminários, reuniões científicas, discussões de artigos de revistas (clube de revistas ou de atualização), sessões de discussão de métodos complementares.

- Sugere-se ainda treinamento em técnicas básicas de pesquisa clínica e noções de metodologia, estatística e pedagogia (ou técnicas de comunicação), com o objetivo de dotar o médico de espírito crítico, discernimento científico e facilidade de comunicação.

B - O treinamento prático sob supervisão deve ser distribuído em:

- unidade de internação para assistência médica a pacientes internados em enfermaria, unidade de emergência, unidade de terapia intensiva;

- unidade ambulatorial, recomendando-se idealmente pelo menos um turno (manhã ou tarde) de ambulatório para seguimento longitudinal de pacientes, durante os dois anos de formação;

- métodos diagnósticos invasivos e não invasivos: mínimo de $10 \%$ da atividade de treinamento.

C - Avaliação: a instituição poderá elaborar critérios próprios, recomendando-se transparência na adoção desses critérios, que deverão conter, além da avaliação subjetiva "em serviço", autoavaliação e escala de atitudes e também critérios objetivos: provas escritas ou práticas. Além disto, a CJTEC-SBC realizará, anualmente, avaliação dos especializandos e residentes de programas credenciados, elaborada por especialistas da SBC, visando às experiências práticas e ao conhecimento teórico. Essas provas serão utilizadas na avaliação tanto do médicoresidente como do serviço em questão, sendo um dos critérios no julgamento dos pedidos de recredenciamento.

\section{Corpo docente}

O supervisor/coordenador do programa deverá ter, além dos pré-requisitos de preceptor, dedicação de tempo de pelo menos 12 horas semanais a atividades relacionadas ao programa.

Os programas devem ter uma proporção mínima de um preceptor por especializando. Pré-requisitos para ser preceptor em Cardiologia:

- Título de especialista em Cardiologia;

- Atuar com compromissos didáticos em atividades como visitas, discussões de casos, discussões de exames, discussões de temas ou outras atividades científicas que possibilitem uma participação efetiva na formação e avaliação dos treinandos, e também do próprio programa.

\section{Centros de treinamento}

Os centros de treinamento devem ter recursos mínimos, incluindo:

A - Ambiente de enfermaria e ambulatório em número e casuística adequados (média de 5 a 8 pacientes da enfermaria sob cuidados de cada especializando e média de atendimento ambulatorial de 5 a 10 pacientes por turno para cada especializando);
B - Eletrocardiografia, teste ergométrico, ecocardiografia Holter, treinamento em radiografia de tórax, laboratório de hemodinâmica com técnicas diagnósticas e de intervenção percutânea. Recomenda-se a exposição ao treinamento em cardiologia nuclear, ressonância e tomografia cardiovascular;

C - Avaliação de pacientes com marca-passos, ressincronizadores e desfibriladores (ambulatório específico de dispositivos implantáveis). Recomenda-se exposição ao treinamento em eletrofisiologia;

D - Unidade de terapia intensiva e/ou unidade coronariana (dois a oito pacientes portadores de cardiopatias para cada especializando) e emergência;

E - Cirurgia cardiovascular com grande atividade (pelo menos duas cirurgias cardíacas por semana), serviço de pré e pós-operatório. Recomenda-se a exposição ao treinamento em transplante cardíaco;

F - Cuidados hospitalares e ambulatoriais de cardiopatias congênitas;

G - Treinamento em prevenção, promoção da saúde e reabilitação;

H - Acesso a bibliotecas eletrônicas e livros de referência em clínica médica e cardiologia;

I - Quando não houver um quesito mínimo na instituição, esta poderá estabelecer convênio com outra instituição, desde que também credenciada pela SBC.

\section{Conteúdo programático do currículo em Cardiologia}

A seguir, apresentam-se aspectos específicos das competências necessárias para atuação em Cardiologia no Brasil. Desta forma, especificam-se áreas do conhecimento em que o formando em Cardiologia deverá ser treinado de modo a desenvolver tais competências.

\section{1. Ética}

Em sua formação, o treinando em Cardiologia deverá desenvolver/aperfeiçoar princípios éticos de comportamento em sua área de atuação. Os três princípios fundamentais são: o bem-estar do paciente, a autonomia e a justiça social.

Ter o bem-estar do paciente como princípio primordial contribui para a tomada de decisão diante de dilemas éticos, sejam burocráticos, econômicos ou políticos. O treinando deverá criar relacionamento ético com o paciente, respeitando os princípios da bioética: autonomia, não maleficência, beneficência.

Ter sensibilidade e respeito à cultura, às crenças, à idade, ao sexo e às limitações físicas do paciente, mantendo o respeito e o sigilo das informações e da privacidade do paciente. O treinando deverá criar uma empatia com o paciente.

A assertiva do princípio da autonomia reza que o médico faz recomendações e o paciente toma a decisão final, devidamente esclarecido.

O conceito de justiça social se aplica ao entendimento de que o médico não atua em um vácuo; ele é parte de um complexo sistema de saúde e precisa se engajar nas regras e melhorias do sistema. 
O treinando deve ser habilitado a promover ações de promoção, prevenção, recuperação e reabilitação da saúde, com senso de responsabilidade social e compromisso com a cidadania, atuando como promotor da saúde integral do ser humano.

O especializando deve ter relacionamento profissional adequado com a equipe de trabalho. Deve também agir com profissionalismo, apresentando integridade, confiabilidade, capacidade de trabalho em grupo, deve saber assistir estudantes, colegas em formação, saber reformular a própria postura conforme necessário e exercer liderança quando for preciso, organizando a equipe no atendimento multiprofissional, como por exemplo, na parada cardiorrespiratória.

O especializando deve redigir relatórios, evoluções em prontuário, prescrições e comunicações de forma organizada, completa e legível.

\section{Anamnese}

Coletar a história clínica de forma lógica e organizada. Reconhecer as diferenças práticas dos pacientes que deveriam estar em diferentes ambientes: pronto-socorro, consultório, unidade de internação, unidade de cuidados intensivos e adaptar a anamnese ao tempo disponível, conforme demandas prioritárias do paciente. Saber ouvir o paciente e usar técnicas não verbais na obtenção de informação.

A - Objetivos:

- obter uma história com relevância para as desordens do aparelho cardiovascular. Investigar:

- presença de sinais/sintomas relacionados ao aparelho cardiovascular;

- história da moléstia atual;

- presença de comorbidades, história clínica pregressa;

- uso de drogas, uso de medicamentos não lícitos;

- outros vícios, hábitos de vida, condições psicossociais e econômicas.

B - Conhecimentos necessários:

- conhecer o significado das palavras utilizadas pelo paciente para descrever seus sintomas;

- sinais/sintomas clássicos das doenças cardiovasculares;

- reconhecer que as doenças nem sempre se apresentam com sinais/sintomas clássicos;

- fatores de risco para as doenças cardiovasculares;

- saber os nomes e efeitos colaterais dos medicamentos utilizados pelo paciente;

- reconhecer os sintomas e saber sobre o tratamento das comorbidades frequentemente associadas com as doenças cardiovasculares.

C - Habilidades:

- analisar e integrar a informação obtida da história do paciente;

- avaliar o risco cardiovascular global.
D - Comportamentos e atitudes:

- estabelecer um relacionamento com o paciente baseado na empatia e confiança;

- conceder o tempo necessário ao paciente para que expresse seus sintomas em suas próprias palavras;

- valorizar primeiro o relato espontâneo do paciente, mas, depois, saber fazer perguntas direcionadas (conhecimento conteúdo-específico);

- considerar a importância da relação das comorbidades e condições sociais com as doenças cardiovasculares.

\section{Exame clínico}

Exame clínico completo, descrevendo as bases fisiológicas e fisiopatológicas para achados normais e anormais. Distinguir achados normais de achados patológicos no exame completo do aparelho cardiovascular.

A - Objetivos:

- complementar os achados subjetivos da anamnese com os achados objetivos do exame físico do aparelho cardiovascular e outros sistemas;

- realizar um exame físico completo do paciente, pesquisando evidência de manifestações cardiovasculares, bem como de doenças associadas;

- examinar os sistemas venoso e arterial periféricos;

- examinar o coração.

B - Conhecimentos necessários:

- reconhecer, ao exame físico, os sinais causados pelas doenças cardiovasculares;

- examinar os pulsos arteriais e suas características nas diferentes artérias (frequência, ritmo e perfil hemodinâmico) e saber medir a pressão arterial;

- ser capaz de examinar o sistema venoso e, em particular, estimar a pressão no átrio direito (pressão venosa jugular);

- examinar as impulsões precordiais. Compreender a fisiologia e fisiopatologia do ciclo cardíaco e, dessa forma, compreender como os sons cardíacos sistólicos e diastólicos, normais e anormais, são formados, e quais manobras são necessárias para melhor auscultá-los;

- fisiopatologia dos sinais clínicos de retenção de fluidos e baixa perfusão.

C - Habilidades:

- avaliação acurada sobre o estado clínico do paciente, com particular ênfase no sistema cardiovascular;

- utilizar o estetoscópio e o esfigmomanômetro para avaliação do coração e vasos sanguíneos;

- medir o índice tornozelo-braquial com o aparelho de pressão aneroide, conhecendo as limitações e as vantagens dessa medida.

D - Comportamentos e atitudes:

- examinar o paciente com respeito à sua dignidade;

- correlacionar continuamente os achados ao exame 
físico, com os achados subsequentes ao ecocardiograma e/ ou cirurgia cardíaca, desta forma enfatizando o aprendizado ao longo da vida.

\section{Exames complementares}

Desenvolver a habilidade de assimilar informações da anamnese e exame clínico, reuni-las no raciocínio para um diagnóstico diferencial com hierarquia de prioridade.

Interpretar corretamente o eletrocardiograma e todos os exames complementares em Cardiologia. Compreender as próprias limitações, sabendo procurar auxílio de colegas e da literatura, sendo ainda capaz de solicitar exames de forma ordenada e fundamentada nos achados e nas hipóteses.

Compreender a lógica bayesiana para o raciocínio diagnóstico: estimar a probabilidade de um diagnóstico conforme a probabilidade pré-teste e a acurácia dos exames solicitados, entendendo por que os exames são suplementares e não eliminam a necessidade da anamnese e do exame clínico. Demonstrar raciocínio apropriado em situações de ambiguidade e incerteza, capacidade de questionar a veracidade de suas próprias crenças, enquanto procura por clareza.

Não confiar cegamente em exames diagnósticos independentemente dos achados clínicos.

Saber revisar a abordagem em face de novas observações e informações.

\subsection{Eletrocardiografia, Holter, teste de esforço}

A - Objetivos:

- selecionar, analisar e interpretar cada uma das técnicas eletrocardiográficas não invasivas.

B - Conhecimentos necessários e habilidades:

- saber identificar o eletrocardiograma (ECG) normal e as anormalidades, em particular: arritmias, bloqueios de ramo, hipertrofia de câmaras, isquemia aguda e crônica, anormalidades do intervalo QT e da repolarização, pericardite, anormalidades secundárias a distúrbios eletrolíticos, disfunção de marca-passo.

C - Comportamentos e atitudes:

- escolher modalidades de técnicas e protocolos de forma útil e custo-efetiva, evitando super e subutilização dos testes;

- integrar os dados das diferentes formas de técnicas eletrocardiográficas, bem como de outras técnicas invasivas e não invasivas.

\subsubsection{Eletrocardiograma}

A - Conhecimentos necessários:

- fisiologia e anatomia do sistema de condução;

- mecanismos celulares e moleculares envolvidos na atividade elétrica do coração;

- princípios básicos do ECG. Compreender a evolução normal dos vetores elétricos durante o ciclo cardíaco;

- reconhecer o ECG normal e como ele é realizado;

- características das sobrecargas atriais e ventriculares, bloqueios de ramo e outros distúrbios da condução, taquicardias, bradicardias, isquemia miocárdica aguda e crônica, pericardite e miocardite, anormalidades eletrolíticas, pré-excitação, anormalidades do intervalo QT e da repolarização ventricular e disfunção de marca-passo.

B - Habilidades:

- realizar e interpretar o ECG no contexto clínico, relacionar os achados às patologias cardiovasculares;

- demonstrar capacidade para selecionar a técnica eletrocardiográfica para a melhor avaliação de um determinado paciente.

C - Comportamentos e atitudes:

- reconhecer as vantagens e limitações do ECG em diversas situações clínicas;

- interagir, cooperar com cardiologistas intervencionistas, cirurgiões cardíacos, anestesistas, eletrofisiologistas, bem como outros médicos envolvidos com medicina de urgência e intensiva;

- reconhecer que o diagnóstico e o tratamento de algumas arritmias, algumas vezes, dependem de uma equipe multidisciplinar;

- explicar ao paciente e à sua família as implicações dos resultados dos exames eletrocardiográficos.

\subsubsection{Holter ou eletrocardiografia ambulatorial de $24 \mathrm{~h}$}

A - Conhecimentos necessários:

- conhecer as indicações para realização desses exames;

- reconhecer as limitações técnicas dos métodos.

B - Habilidades:

- interpretar o Holter nos diversos contextos clínicos.

C - Comportamentos e atitudes:

- reconhecer as vantagens e limitações desses exames na prática clínica;

- explicar ao paciente e à sua família as implicações dos resultados obtidos com o Holter.

\subsubsection{Teste de esforço e teste cardiopulmonar de exercício}

A - Conhecimentos necessários:

- principais indicações do teste de esforço;

- principais indicações do teste cardiopulmonar;

- conhecer as contraindicações, limitações e complicações desses métodos;

- identificar e saber abordar as possíveis complicações durante o exame;

- conhecer os critérios para interrupção do teste;

- conhecer as implicações médico-legais do teste de esforço.

B - Habilidades:

- realizar e interpretar o teste de esforço e interpretar o teste cardiopulmonar;

- abordar as complicações de forma adequada e com agilidade. 
C - Comportamentos e atitudes:

- reconhecer as vantagens e limitações do teste de esforço e do cardiopulmonar na prática clínica;

- explicar ao paciente e à sua família as implicações dos resultados obtidos com o teste de esforço e o cardiopulmonar.

4.2. Exames de imagem não invasivos: radiografia de tórax, ecocardiograma, RNM, TC cardíaca e cardiologia nuclear

A - Objetivos:

- indicar e interpretar adequadamente os métodos de imagem: Radiografia de tórax, ecocardiograma, tomografia computadorizada (TC), ressonância nuclear magnética (RNM), técnicas nucleares.

B - Conhecimentos necessários:

- utilizar os exames não invasivos para avaliar estrutura e função cardíacas;

- avaliar doenças cardiovasculares e doenças que tenham repercussão sobre o aparelho cardiovascular.

C - Comportamentos e atitudes:

- escolher a técnica de imagem para situações clínicas específicas;

- escolher a técnica, modalidades e protocolos de imagem adequados e custo-efetivos, evitando super e subutilização dos exames;

- integrar os dados dos diferentes exames complementares;

- manter-se atualizado com a utilização dos diversos exames de imagem.

\subsubsection{Ecocardiografia}

A - Conhecimentos necessários:

- técnicas e modalidades: modo M, modo bidimensional, Doppler de fluxo sanguíneo convencional e tecidual, ecocardiograma transtorácico, sob estresse, com contraste, transesofágico e tridimensional;

- saber suas indicações, contraindicações, limitações e complicações.

B - Habilidades:

- interpretar os resultados dos ecocardiogramas transtorácico, transesofágico e sob estresse.

C - Comportamentos e atitudes:

- reconhecer as vantagens e limitações do ecocardiograma na prática clínica;

- explicar ao paciente e à sua família as implicações dos resultados obtidos com o exame;

- interagir, cooperar com cardiologistas intervencionistas, cirurgiões cardíacos, anestesistas, eletrofisiologistas, bem como com outros médicos envolvidos com áreas de imagem correlatas.

\subsubsection{Tomografia computadorizada cardíaca}

A - Conhecimentos necessários:

- técnicas e modalidades bi e tridimensionais, TC ultrarrápida, angiograma coronariano;
- saber suas indicações, contraindicações, limitações e complicações.

B - Habilidades:

- avaliar e interpretar a TC no contexto clínico.

C - Comportamentos e atitudes:

- interagir com técnicos de radiologia, radiologistas e outros profissionais.

\subsubsection{Ressonância nuclear magnética (RNM) cardíaca}

A - Conhecimentos necessários:

- modo bidimensional, imagem de perfusão, realce tardio, cinerressonância, angiorressonância, imagem TI;

- saber suas indicações, contraindicações, limitações e complicações.

B - Habilidades:

- selecionar as indicações apropriadas de RNM para pacientes com doença cardiovascular suspeita ou conhecida, e avaliar/interpretar o exame no contexto clínico de cada paciente.

C - Comportamentos e atitudes:

- interagir com técnicos de radiologia, radiologistas e outros profissionais.

\subsubsection{Cardiologia nuclear}

A - Conhecimentos necessários:

- técnicas: angiografia planar, tomografia computadorizada por emissão de fóton único (SPECT), Gated SPECT (SPECT Com sincronização eletrocardiográfica), Gated blood pool SPECT (ventriculografia radioisotópica), tomografia por emissão de pósitrons ( $P E T)$, exames de repouso e de estresse (físico ou farmacológico);

- traçadores: tálio, tecnécio, fluorodeoxiglicose, metaiodobenzilguanidina;

- saber suas indicações, contraindicações, limitações e complicações.

B - Habilidades:

- avaliar e interpretar os exames nucleares no contexto clínico.

C - Comportamentos e atitudes:

- escolher a modalidade de estresse apropriada para cada paciente dependendo do contexto clínico;

- cooperar com médicos nucleares e técnicos;

- reconhecer o risco da radiação ionizante para o paciente e funcionários.

4.3. Exames de imagem invasivos: cateterização e angiografia

A - Objetivos:

- interpretar angiogramas de coronárias nativas, pontes/ enxertos e ventriculografia;

- interpretar cateterização do coração direito e esquerdo e artérias coronárias e periféricas: renais, artéria mesentérica, artérias dos membros, artérias carótidas e vertebrais. 
B - Conhecimentos necessários:

- princípios da fluoroscopia, radiação e segurança;

- saber as indicações, contraindicações, limitações e complicações da cateterização cardíaca e angiografia;

- delineamento da anatomia radiológica do coração, aorta, grandes vasos, artérias coronárias, bem como das artérias utilizadas como acesso vascular durante a cateterização (artérias femoral, radial e braquial);

- ondas de pressões obtidas durante o cateterismo;

- rotina de coleta de dados hemodinâmicos e oximétricos, cálculo do débito cardíaco, resistências vasculares, áreas valvares e quantificação de shunts;

- conhecer as diferentes técnicas e os diferentes tipos de cateteres utilizados na arteriografia coronariana e no cateterismo cardíaco;

- conhecer indicações e riscos da técnica de cateterismo transeptal;

- saber quando e como realizar pericardiocentese, implante de marca-passo provisório, e as potenciais complicações associadas com seu uso;

- conhecer os princípios básicos e indicações para ultrassom intracoronário, Doppler e avaliação de pressões;

- demonstrar familiaridade com técnicas angiográficas e hemodinâmicas.

C - Habilidades:

- demonstrar capacidade para abordar arritmias ameaçadoras da vida e outras situações de emergência ocorridas no laboratório de cateterismo, incluindo ressuscitação e suporte de vida;

- avaliar os angiogramas, ventriculogramas, aortogramas, angiogramas pulmonares e arteriografias periféricas em estados normal e patológico.

D - Comportamentos e atitudes:

- auxiliar na informação e no esclarecimento adequado ao paciente com relação às limitações, aos riscos e aos aspectos do procedimento a ser realizado, transmitindo segurança e dirimindo as dúvidas, sempre com a orientação dos preceptores;

- ser treinado para assumir responsabilidade na solicitação e interpretação dos testes invasivos, considerando a relação risco/benefício do exame;

- ser treinado para selecionar a modalidade de tratamento adequada (clínica, percutânea ou cirúrgica), baseando-se nos resultados do cateterismo e considerando o contexto clínico de cada paciente;

- interagir com técnicos, médicos especializados (intervencionistas, eletrofisiologistas, cardiologistas pediátricos), quando necessário.

\section{Prevenção e promoção da saúde}

\section{A - Objetivos:}

- avaliar e tratar pacientes com fatores de risco para doenças cardiovasculares;
- avaliar como agem os diferentes métodos de prevenção;

- conhecer as doenças cardiovasculares e fatores de risco na comunidade local;

- contribuir para o esforço global em reduzir a morbimortalidade, passando a mensagem ao público da prevenção e controle dos fatores de risco;

- abordar a prevenção de uma forma holística, compreendendo a potenciação do risco cardiovascular pelo agrupamento dos fatores de risco.

B - Conhecimentos necessários:

- epidemiologia das doenças cardiovasculares na comunidade local;

- fatores de risco descrevendo a distribuiçãa e a frequência das condições de alto risco na comunidade local;

- avaliações de risco: prevenção primária, prevenção secundária, interação de risco multifatorial, escores de risco;

- orientar dieta e nutrição em relação à abordagem do risco cardiovascular;

- estratégias de prevenção e tratamento para fatores de risco;

- reconhecer que os fatores de risco geralmente são associados e requerem uma abordagem multidisciplinar;

- complicações e consequências de fatores de risco específicos.

C - Habilidades:

- avaliar o risco cardiovascular e os benefícios da prevenção para o indivíduo e para a população;

- abordar os fatores de risco apropriadamente, comunicar sua importância ao paciente, seus familiares e à comunidade.

D - Comportamentos e atitudes:

- considerar a importância da abordagem dos fatores de risco;

- considerar a variação dos fatores de risco cardiovasculares de acordo com a população, fatores socioeconômicos, sexo e grupos raciais;

- encorajar o paciente a adotar um estilo de vida saudável, com ênfase específica no controle dos fatores de risco e manutenção de um perfil de risco favorável ao longo da vida;

- oferecer suporte e aconselhamento para membros de famílias com doenças cardiovasculares hereditárias;

- cooperar com equipe multiprofissional;

- participar ativamente de programas de prevenção de doenças cardiovasculares;

- considerar a custo-efetividade do regime de tratamento prescrito.

\section{A interconsulta cardiológica}

\subsection{Consulta para avaliação pré-operatória para cirurgia não cardíaca}

A - Objetivos:

- indicar corretamente a avaliação complementar préoperatória; 
- integrar informações com relação aos efeitos estimados do estresse cirúrgico;

- ser capaz de avaliar o risco cardiovascular e participar do processo de decisão em relação ao risco-benefício da cirurgia não cardíaca (sobrevida estimada, impacto da doença cardiovascular x benefícios da cirurgia não cardíaca).

B - Conhecimentos necessários:

- compreender que os procedimentos indicados na propedêutica cardiovascular pré-operatória devem ser realizados por indicação feita pela doença cardiovascular, e não em razão da cirurgia não cardíaca;

- exames pré-operatórios somente devem ser realizados se forem resultar em mudança na abordagem do paciente no período perioperatório e a longo prazo;

- aplicar corretamente as técnicas de imagem para avaliação pré-operatória, quando indicado.

C - Habilidades:

- estimar adequadamente o risco cardiovascular e sugerir condutas que o diminuem.

D - Comportamentos e atitudes:

- comunicar aos pacientes as implicações dos resultados dos testes pré-operatórios na abordagem perioperatória. Comunicar os potenciais riscos do atraso da cirurgia não cardíaca e os benefícios da terapia/cirurgia cardíaca;

- interagir com outros especialistas envolvidos nos cuidados perioperatórios;

- reconhecer as limitações dos vários testes de imagem.

6.2. Interconsulta com a Neurologia em pacientes com sintomas neurológicos isquêmicos ou acidente vascular encefálico

A - Objetivos:

- pesquisar fontes potenciais de embolia cardíaca e orientar abordagem adequada;

- pesquisar outras manifestações de aterosclerose.

B - Conhecimentos necessários:

- fibrilação atrial;

- conhecer o mecanismo, probabilidade e opções de tratamento para a embolia de fonte cardíaca e da aorta;

- estar alerta para a frequência de doença arterial coronariana e outras doenças arteriais ateroscleróticas nos pacientes com doença neurológica isquêmica.

C - Habilidades:

- saber indicar o ecocardiograma transesofágico para pesquisa de potenciais fontes de embolia;

- propor uma avaliação mais ampla do paciente para investigação de outras manifestações de doença aterosclerótica e aconselhar tratamento e abordagem de risco.

D - Comportamentos e atitudes:

- compreender importância do diagnóstico e tratamento de doenças cardiovasculares coexistentes;

- considerar as fontes potenciais de embolia.

\subsection{Interconsulta cardíaca com outras especialidades}

A - Objetivos:

- avaliar frequência do sintoma cardíaco, problemas relacionados a outras doenças associadas e ser capaz de proporcionar um seguimento e uma abordagem adequados;

- conhecer as complicações cardiovasculares de quimioterápicos e radioterapia.

B - Habilidades:

- ser capaz de antecipar os problemas cardiovasculares nos casos de doenças primariamente não cardíacas, quimioterapia e radioterapia.

C - Comportamentos e atitudes:

- cooperar com outros especialistas e outros profissionais da área de saúde e oferecer pronto suporte às suas necessidades.

\section{Genética}

A - Objetivos:

- ser capaz de realizar avaliação cardiológica geral e tratamento de pacientes com doenças cardiovasculares de origem hereditária ou familiar.

B - Conhecimentos necessários:

- conhecer a incidência e a prevalência das doenças hereditárias cardiovasculares;

- conhecimentos básicos sobre embriologia cardíaca e família de genes envolvidos na cardiogênese;

- conhecer os princípios da herança mendeliana;

- conhecer os princípios das doenças cardiovasculares poligênicas (tais como HAS, DM, dislipidemia);

- conhecer as doenças cardiovasculares monogênicas: miocardiopatia hipertrófica, aortopatia (como Síndrome de Marfan, de Ehlers-Danlos e de Williams), miocardiopatias dilatadas familiares, canalopatias familiares, desordens familiares da septação, trissomias (em especial trissomia do 21), base familiar das anomalias conotruncais e dislipidemias familiares (hipercolesterolemia familiar e hiperlipidemia familiar combinada).

C - Habilidades:

- avaliar história familiar e construir árvore genealógica;

- distinguir padrões de herança: autossômica dominante, autossômica recessiva, ligada ao X e mitocondriais;

- demonstrar como aconselhar os casos índices, membros da família (probabilidade de ser afetado por uma desordem genética cardiovascular);

- reconhecer problemas com relação à interpretação de árvore genealógica, tais como penetrância incompleta, expressividade variável e padrões de expressividade relacionados à idade.

D - Comportamentos e atitudes:

- cooperar com geneticistas clínicos;

- desenvolver um método sistemático de abordar famílias com uma potencial doença cardiovascular hereditária; 
- explicar, educar e informar pacientes sobre a natureza de sua doença, os testes diagnósticos utilizados (possibilidade de falso positivo e negativo);

- realizar consultas com médicos de outras especialidades, quando necessário, para completa avaliação dos pacientes com desordens genéticas.

\section{Farmacologia clínica}

\section{A - Objetivos:}

- dominar a teoria e a prática do tratamento farmacológico das doenças cardiovasculares.

B - Conhecimentos necessários:

- a classificação e o modo de ação dos medicamentos, com ênfase nos inibidores da enzima conversora da angiotensina, bloqueadores do receptor da angiotensina, antagonistas da aldosterona, anti-hipertensivos de ação central, medicamentos antiarrítmicos, betabloqueadores, bloqueadores dos canais de cálcio, diuréticos, medicamentos redutores de lípides, agentes antiplaquetários, anticoagulantes, inotrópicos, digitálicos, nitratos, outros medicamentos vasodilatadores, medicamentos cardiotóxicos, inibidores da renina e bloqueadores dos canais de potássio;

- além da classificação e modo de ação, reconhecer também, nesses medicamentos, a farmacocinética (absorção, biodisponibilidade, distribuição, biotransformação, excreção), farmacodinâmica, farmacogenética, indicações, contraindicações, interações, efeitos adversos e toxicidade;

- realizar e interpretar testes diagnósticos para avaliar eficácia e segurança dos medicamentos (testes laboratoriais, ECG, monitoração hemodinâmica, ecocardiograma).

C - Habilidades:

- adquirir dados sobre o uso de medicamentos (prévio e atual);

- avaliar os riscos e benefícios de prescrever um determinado medicamento;

- monitorar os efeitos desejáveis e os efeitos colaterais, e, nesse caso, ser capaz de fazer modificações apropriadas no esquema terapêutico;

- reconhecer e saber abordar possíveis interações medicamentosas;

- avaliar o delineamento e os resultados de estudos clínicos publicados;

- identificar e incorporar a importância de ervas medicinais usadas pelo paciente, pelo risco de eventos adversos e interações farmacológicas.

D - Comportamentos e atitudes:

- incorporar os princípios da terapia baseada em evidências e diretrizes atuais na prática clínica;

- orientar, discutir com o paciente e seus familiares para melhorar a aderência ao tratamento e garantir reconhecimento precoce de possíveis efeitos colaterais;

- considerar a custo-efetividade e a plausibilidade de prescrever determinado regime de tratamento;
- saber utilizar ferramentas eletrônicas de busca de interações medicamentosas.

\section{Hipertensão arterial sistêmica}

A - Objetivos:

- diagnosticar e tratar diferentes formas de hipertensão arterial;

- avaliar complicações cardíacas e de outros órgãos-alvo (rins, encéfalo, retina, artérias) em pacientes hipertensos.

B - Conhecimentos necessários:

- epidemiologia, etiologia, fisiopatologia, história natural e evolução clínica da hipertensão arterial primária;

- descrever o diagnóstico e a avaliação dos pacientes hipertensos;

- avaliação da pressão arterial, incluindo as indicações da monitoração ambulatorial da pressão arterial (MAPA) e monitoração residencial da pressão arterial (MRPA);

- sinais e sintomas de lesões em órgãos-alvo;

- definir hipertensão arterial secundária e suas várias etiologias, epidemiologia, fisiopatologia, história natural, evolução clínica, prognóstico e terapêutica da hipertensão arterial secundária;

- saber reconhecer as diversas formas de elevação aguda da pressão arterial e seu manejo em sala de emergência.

C - Habilidades:

- conhecer a metodologia correta de aferição da pressão arterial, visando ao diagnóstico e acompanhamento clínico ideal da hipertensão;

- Exame oftalmoscópico: conhecer as indicações clínicas, interpretação e limitações do método;

- MAPA e MRPA: conhecer as corretas indicações clínicas, princípios básicos de interpretação e limitações do método;

- aconselhar pacientes com relação ao estilo de vida e aderência ao tratamento;

- ensinar aos pacientes a medir sua própria pressão arterial da maneira correta;

- selecionar parâmetros apropriados de forma a descrever o perfil de risco cardiovascular em um paciente individual com hipertensão.

D - Comportamentos e atitudes:

- reconhecer que, para o diagnóstico e o tratamento da hipertensão, é necessária uma abordagem multidisciplinar;

- ser capaz de motivar o paciente para manter aderência em longo prazo com o tratamento anti-hipertensivo.

\section{Dislipidemia}

A - Objetivos:

- diagnosticar e tratar diferentes formas de dislipidemias;

- avaliar as complicações cardíacas e extracardíacas da dislipidemia;

- avaliar o risco de doença cardiovascular de forma adequada para prescrição de hipolipemiantes de acordo com o grau de risco. 
B - Conhecimentos necessários:

- epidemiologia, etiologia e fisiopatologia da dislipidemia;

- complicações e as consequências da dislipidemia;

- diagnóstico e abordagem da dislipidemia;

- biologia da aterosclerose;

- dominar ferramentas de avaliação de risco cardiovascular;

- farmacologia dos medicamentos hipolipemiantes.

C - Habilidades:

- abordar a dislipidemia usando métodos corretos para diagnóstico e controle terapêutico;

- aconselhar o paciente para mudanças no estilo de vida e aderência ao tratamento;

- aconselhar o paciente a fazer exame periódico para avaliação dos lípides;

- convocação de familiares para triagem e tratamento em casos de suspeita de dislipidemias genéticas;

- utilizar adequadamente o escore de risco de Framingham;

- indicar adequadamente o uso de agravantes de risco coronário;

- selecionar tratamento adequado para redução dos lípides a níveis satisfatórios e prevenir/tratar as consequências das dislipidemias;

- selecionar parâmetros apropriados para descrever o perfil de risco de um paciente individual;

- identificar outras áreas vasculares afetadas pela aterosclerose;

- abordar regimes de tratamento com diversos medicamentos, de acordo com as comorbidades dos pacientes e possíveis efeitos colaterais.

D - Comportamentos e atitudes:

- reconhecer que, às vezes, é necessária abordagem multidisciplinar para o diagnóstico e tratamento das dislipidemias;

- ser capaz de motivar o paciente para manter aderência ao tratamento a longo prazo;

- reconhecer que os fatores de risco estão geralmente associados, de modo a formular um esquema integrado para abordagem do paciente.

\section{Diabete melito}

\section{A - Objetivos:}

- diagnosticar e tratar complicações cardiovasculares no paciente diabético.

B - Conhecimentos necessários:

- definir diabete melito (DM);

- conhecer o papel do DM na doença arterial coronariana, nas seguintes áreas:

- epidemiologia;
- fisiopatologia das complicações cardiovasculares;

- importância da intervenção nos fatores de risco;

- triagem para doenças cardiovasculares nos pacientes com DM;

- triagem para DM nos pacientes com doenças cardiovasculares;

- descrever a fisiopatologia do DM e suas complicações cardíacas e não cardíacas;

- delinear o tratamento para o paciente diabético: dieta, exercício, medicamentos hipoglicêmicos e insulina;

- conhecimento das metas terapêuticas em pacientes diabéticos.

C - Habilidades:

- abordar a prevenção, o diagnóstico e o tratamento do DM e as complicações cardiovasculares associadas;

- participar ativamente de equipe multidisciplinar de forma a tratar adequadamente o paciente diabético, de acordo com a fase da doença e a existência de complicações.

D - Comportamentos e atitudes:

- compreender a necessidade de abordagem multidisciplinar do paciente diabético;

- estar alerta para compreender e abordar adequadamente o paciente, desde a prevenção primária até a fase das lesões de órgãos-alvo;

- reconhecer que os fatores de risco estão geralmente associados, de modo a formular um esquema integrado para abordagem do paciente.

\section{Tabagismo}

A - Objetivos:

- avaliar pacientes tabagistas, estratificando o risco cardiovascular e orientando a cessação do tabagismo.

B - Conhecimentos necessários:

- efeitos cardiovasculares do tabagismo;

- estratificação de risco;

- tratamento, efeitos adversos e programas de cessação do tabagismo;

- efeitos da cessação sobre o prognóstico.

C - Habilidades:

- conhecer as preocupações do paciente em relação ao fumo;

- reconhecer a dificuldade causada pela dependência;

- reconhecer pacientes refratários que precisam encaminhamento para programas de cessação.

D - Comportamentos e atitudes:

- aconselhar e solicitar enfaticamente a todos os fumantes que abandonem o vício;

- saber motivar e auxiliar o paciente no processo de abandono;

- encaminhar quando necessário. 


\section{Síndromes coronarianas agudas}

\section{A - Objetivos:}

- ser capaz de realizar avaliação especializada e tratamento dos pacientes com síndromes coronarianas agudas (SCA).

B - Conhecimentos necessários:

- aspectos principais da fisiopatologia das SCA: isquemia miocárdica, aterosclerose das artérias epicárdicas, eventos que precipitam SCA, doença arterial coronariana não ateromatosa;

- características clínicas das SCA: dor torácica cardíaca isquêmica, exame do sistema cardiovascular nas SCA, isquemia e infarto silenciosos;

- classificar os diferentes tipos de SCA e definir o tipo de tratamento mais apropriado para determinada situação clínica;

- procedimentos diagnósticos para os pacientes com SCA: análise dos sintomas, diagnóstico diferencial, ECG de 12 derivações, exames laboratoriais, exames de imagem;

- descrever as potenciais complicações das SCA: arritmias, complicações mecânicas;

- descrever as opções de tratamento para SCA: terapia farmacológica hospitalar e pré-hospitalar, intervenção coronária percutânea, cirurgia de revascularização do miocárdio (CRVM);

- características especiais das manifestações em mulheres, idosos e diabéticos.

C - Habilidades:

- considerar o papel dos fatores de risco, as características clínicas da oclusão coronariana e seu curso clínico;

- identificar e classificar a dor torácica;

- interpretar os marcadores bioquímicos de lesão miocárdica;

- interpretar o ECG e as técnicas de imagem para detectar localização da isquemia ou infarto;

- compreender a importância de monitorar o paciente com SCA;

- providenciar tratamento farmacológico adequado;

- compreender as indicações e contraindicações do tratamento de reperfusão aguda e tomar decisões adequadas;

- saber indicar cinecoronariografia no contexto da SCA;

- demonstrar capacidade para tratar pacientes com insuficiência cardíaca, choque cardiogênico, incluindo monitoração hemodinâmica invasiva.

D - Comportamento e atitudes:

- reconhecer a necessidade de equipe organizada e treinada em atendimento de urgência para abordagem ótima dos pacientes com SCA;

- tomada rápida de decisões, desde a chegada do paciente ao departamento de urgência até a terapia definitiva ser estabelecida

- considerar o estresse que uma doença aguda e grave causa no paciente e em sua família;

- reconhecer quando é necessário transferir o paciente para outro hospital para intervenção percutânea ou CRVM;
- contribuir para o esclarecimento da comunidade sobre o significado da dor torácica e a necessidade de avaliação precoce.

\section{Doença arterial coronariana crônica}

A - Objetivos:

- realizar uma avaliação e tratamento dos pacientes com doença arterial coronariana (DAC) crônica;

- avaliar o paciente e ser capaz de interpretar os resultados dos exames complementares;

- selecionar uma terapia adequada.

B - Conhecimentos necessários:

- epidemiologia e fatores de risco da DAC crônica;

- biologia celular e molecular da DAC, sua fisiopatologia e os efeitos da isquemia no miócito;

- eventos que podem precipitar uma crise de angina;

- prognóstico de pacientes com DAC crônica;

- avaliação clínica da DAC crônica suspeita ou conhecida, incluindo avaliação da dor torácica, outros sinais e sintomas e procedimentos diagnósticos;

- abordagem da DAC crônica, incluindo mudança do estilo de vida, abordagem farmacológica (medicamentos modificadores da história natural da doença e para controle dos sintomas);

- explicar o papel e a indicação das terapias clínica e de revascularização (angioplastia ou CRVM).

C - Habilidades:

- demonstrar habilidade para estratificação de risco dos pacientes e seleção de uma estratégia de abordagem apropriada;

- selecionar, solicitar e interpretar corretamente métodos propedêuticos, invasivos e não invasivos, para avaliação de isquemia, viabilidade, função ventricular esquerda e anatomia coronariana;

- identificar e tratar os fatores de risco para DAC estável.

D - Comportamentos e atitudes:

- reconhecer a importância da abordagem dos fatores de risco na prevenção secundária;

- consultar especialistas (hemodinamicistas, cirurgiões cardíacos, nutricionistas, endocrinologistas) quando necessário, de forma a proporcionar uma ampla e adequada abordagem do paciente com DAC estável.

\section{Intervenção coronariana percutânea}

A - Objetivos:

- compreender as indicações, técnicas, complicações agudas e a longo prazo, limitações, alternativas e farmacoterapia adjunta necessária.

B - Conhecimentos necessários:

- principais técnicas de angioplastia (angioplastia com balão, implante de stents, aterectomia rotacional);

- características fundamentais dos balões e stents (comprimento, diâmetro, cobertura com drogas antiproliferativas); 
- compreender o problema da reestenose, trombose dos stents, de forma a pesar riscos e benefícios do tratamento percutâneo;

- reconhecer o risco aumentado dos pacientes diabéticos e com insuficiência renal;

- estar alerta para as complicações agudas e crônicas da angioplastia;

- indicações atualizadas para angioplastia e CRVM, bem como o tratamento conservador da doença arterial coronariana (DAC), com relação à anatomia, à extensão da doença e ao papel da função ventricular esquerda no contexto das SCA e da DAC estável;

- conhecer a terapia de drogas adjuvantes, em particular regimes de anticoagulação e antiagregantes plaquetários.

D - Habilidades:

- selecionar apropriadamente pacientes com SCA que são candidatos à angiografia e à angioplastia de urgência;

- selecionar apropriadamente pacientes com DAC crônica que são candidatos à angiografia e à angioplastia;

- prescrever tratamento adequado pré e pós-angioplastia (especialmente anticoagulação, antiagregação plaquetária);

- estar alerta para possíveis complicações, tais como nefropatia pelo contraste, complicações relacionadas aos acessos arteriais (hematoma, fístula, pseudoaneurisma), resistência às drogas. Estar alerta também para a possibilidade de intervenções em doenças não cardíacas, com risco de sangramento enquanto em uso de antiplaquetários.

E - Comportamentos e atitudes:

- explicar para os pacientes e familiares os riscos, benefícios e alternativas para o tratamento.

- Levar em conta os desejos do paciente, comorbidades e situação social para tomar a melhor decisão terapêutica para um determinado paciente;

- interagir e cooperar com outros profissionais: cirurgiões cardíacos, hemodinamicistas, médicos assistentes.

\section{Miocardiopatias}

\section{A - Objetivos:}

- ser capaz de realizar avaliação especializada e tratamento dos pacientes com miocardiopatia e miocardite.

B - Conhecimentos necessários:

- epidemiologia das miocardiopatias: dilatada, Doença de Chagas, periparto, tóxicas, hipertrófica, restritiva, infiltrativa, miocárdio não compactado e endomiocardiofibrose;

- descrever a patologia incluindo genética, características clínicas e critérios diagnósticos das miocardiopatias;

- evolução clínica, fatores desencadeantes de descompensação e internação, riscos de arritmia e morte súbita;

- conhecimento sobre a abordagem clínica e invasiva das miocardiopatias: indicações, contraindicações e possíveis complicações;

- conhecer os indicadores de prognóstico.
C - Miocardite:

- definir miocardite e descrever a etiologia;

- descrever as características clínicas, patologia e critérios diagnósticos de miocardite infecciosa e não infecciosa;

- conhecer o tratamento para as diferentes formas de miocardite e suas complicações.

D - Habilidades:

- interpretar os exames diagnósticos (ECG, Holter, ecocardiograma, teste de esforço, raio x de tórax, cateterismo cardíaco, angiografia coronária, RNM, cintilografia miocárdica, biopsia endomiocárdica, avaliação genética);

- selecionar tratamento adequado e medidas de suporte (clínico, intervencionista, cirúrgico, implante de desfibriladores, ressincronizadores, aparelhos de assistência mecânica, balão intra-aórtico, outros);

- avaliar indicação para transplante cardíaco;

- avaliar indicação para biopsia endomiocárdica, considerando rendimento diagnóstico e potenciais riscos do procedimento.

E - Comportamentos e atitudes:

- trabalhar em conjunto com outros especialistas com o intuito de estabelecer o diagnóstico e planejar a abordagem terapêutica (imunologistas, infectologistas, geneticistas, cirurgiões cardíacos, hemodinamicistas, especialistas em propedêutica complementar cardiológica);

- aconselhar pacientes e seus familiares com relação aos riscos e prognóstico.

\section{Cardiopatia chagásica}

\section{A - Objetivos:}

- capacitação em reconhecer a doença dentro do seu contexto epidemiológico;

- diagnosticar e tratar a Doença de Chagas em suas distintas formas de comprometimento cardíaco.

B - Conhecimentos gerais

- aspectos etiológicos;

- modos de transmissão;

- aspectos epidemiológicos no contexto socioeconômico, regional e cultural;

- formas da doença;

- patologia e imunopatologia da Doença de Chagas;

- manifestações de insuficiência cardíaca, arrítmicas e tromboembólicas;

- tratamento das diferentes formas;

- transplante cardíaco e suas particularidades em Doença de Chagas.

C - Habilidades:

- correto diagnóstico de suas diferentes formas de apresentação;

- conhecimento de fármacos para tratamento etiológico;

- conhecimento de fármacos para tratamento da insuficiência cardíaca,de antiarrítmicos apropriados e anticoagulantes; 
- conhecimento das características, indicação e acompanhamento de dispositivos eletrônicos implantáveis.

D - Comportamento e atitudes:

- reconhecimento da franca relação de carência socioeconômica, via de regra, do portador e do seu grau de desamparo social;

- interagir com setores da assistência social;

- interação com reguladores dos sistemas de saúde;

- aconselhamento quanto à inserção em mercado de trabalho.

\section{Doença pericárdica}

\section{A - Objetivos:}

- ser capaz de realizar avaliação especializada e tratamento adequado dos pacientes com doenças pericárdicas.

B - Conhecimentos necessários:

- classificar e definir pericardite aguda (infecciosa, idiopática, neoplásica), pericardite crônica, pericardite constritiva;

- descrever epidemiologia, fisiopatologia e etiologia de cada uma delas;

- descrever propedêutica relevante invasiva e não invasiva;

- explicar e traçar o diagnóstico diferencial de pericardite constritiva e miocardiopatia restritiva;

- descrever a abordagem de pacientes com pericardite;

- ter conhecimento das complicações relacionadas: derrame pericárdico, tamponamento cardíaco e fisiologia constritiva.

C - Habilidades:

- demonstrar conhecimento sobre as anormalidades do ECG na pericardite aguda;

- selecionar e saber indicar as modalidades de exames de imagem não invasiva: ecocardiograma, RNM, TC; bem como os métodos invasivos;

- avaliar repercussão hemodinâmica;

- determinar etiologia do derrame pericárdico;

- diferenciar clinicamente pericardite de isquemia miocárdica;

- indicar pericardiocentese em pacientes apropriadamente selecionados.

D - Comportamentos e atitudes:

- estar atento para a suspeita diagnóstica, realização do diagnóstico diferencial e estratégia terapêutica para cada caso.

\section{Tumores cardíacos}

\section{A - Objetivos:}

- ser capaz de realizar avaliação especializada e tratamento de pacientes com tumores cardíacos.

B - Conhecimentos necessários:

- epidemiologia, fisiopatologia, patogenia e manifestações clínicas dos tumores cardíacos primários e metástases cardíacas;
- conhecer o efeito do tamanho e localização dos tumores na dinâmica do coração;

- conhecer a repercussão clínica: prejuízo da função cardíaca, manifestações sistêmicas, embolia pulmonar e sistêmica, sinais de obstrução mecânica ao fluxo de sangue, envolvimento pericárdico (constrição e tamponamento);

- identificar os procedimentos diagnósticos apropriados: ecocardiograma, TC, RNM;

- conhecer a abordagem cirúrgica (remoção tumoral, transplante cardíaco, tratamento paliativo).

\section{C - Habilidades:}

- selecionar e solicitar adequadamente os exames de imagem;

- considerar o diagnóstico diferencial de neoplasia primária ou secundária envolvendo o coração;

- reconhecer outras massas cardíacas incluindo trombos e vegetações.

D - Comportamentos e atitudes:

- trabalhar em conjunto com cirurgiões cardiovasculares e oncologistas;

- considerar a importância do suporte, orientações para o paciente e sua família.

\section{Doença cardíaca congênita}

\section{A - Objetivos:}

- ser capaz de avaliar, abordar e apropriadamente encaminhar pacientes com doença cardíaca congênita, submetidos ou não à cirurgia cardíaca prévia.

B - Conhecimentos necessários:

- epidemiologia, etiologia, prevenção, fisiopatologia, nomenclatura das cardiopatias congênitas e circulação fetal;

- identificar patologia, dados para o diagnóstico e abordagem das condições específicas.

C - Habilidades:

- selecionar e indicar corretamente técnicas de imagem e procedimentos invasivos para diagnóstico e tratamento;

- seguimento do paciente a longo prazo, tratamento farmacológico, indicação de tratamento cirúrgico, mudanças de estilo de vida.

D - Comportamento e atitudes:

- compreender a importância de referir pacientes para opinião de especialistas quando necessário;

- orientar paciente e família, considerar a importância do aconselhamento genético;

- considerar a importância das dificuldades emocionais e sociais vividas pelo paciente com cardiopatia congênita.

\section{Cardiologia na mulher}

\section{A - Objetivos:}

- ser capaz de realizar avaliação cardiovascular e tratamento de mulheres gestantes e no puerpério;

- ser capaz de realizar acompanhamento clínico de gestantes portadoras de cardiopatia; 
- identificar as peculiaridades características do sexo feminino, no tocante à prevenção, diagnóstico e tratamento das cardiopatias.

B - Conhecimentos necessários:

- ao avaliar uma gestante, saber identificar as alterações fisiológicas relacionadas ao aparelho cardiovascular na gravidez e suas repercussões em portadoras de cardiopatia;

- doenças e condições cardiovasculares que podem comprometer a saúde, em especial da mulher na gravidez;

- contraindicações para gestação e indicações para a interrupção da gravidez;

- identificar mulheres portadoras de cardiopatias com alto risco de complicações cardíacas durante a gestação;

- conhecer como deve ser o seguimento clínico dessas pacientes;

- situações que necessitam tratamento farmacológico;

- tratamento da hipertensão e suas complicações;

- situações nas quais a intervenção cirúrgica pode ser necessária;

- repercussões cardiovasculares das modalidades de parto;

- conhecer a abordagem da terapia de anticoagulação na gestação;

- diagnosticar e tratar miocardiopatia periparto;

- conhecer eficácia, riscos e contraindicações aos vários métodos contraceptivos de acordo com o tipo de doença cardíaca;

- conhecer perfil de segurança de medicamentos utilizadas na gravidez e lactação, riscos e complicações potenciais associadas ao uso desses fármacos.

C - Habilidades:

- saber os riscos cardiovasculares associados ao uso de hormônios femininos, como contraceptivos ou reposição hormonal:

- realizar avaliação clínica e interpretar resultados de exames complementares de forma a avaliar o risco de uma portadora de cardiopatia que deseja engravidar;

- indicar intervenção cardíaca preventiva, se necessário;

- realizar avaliação clínica e complementar cardiológica durante a gravidez;

- selecionar medicamentos adequados para uso durante a gravidez;

- avaliar o risco fetal e maternal de diferentes intervenções cardíacas;

- acompanhar, avaliar a condição cardiovascular no período pós-parto;

- avaliar o risco de gestações subsequentes.

D - Comportamentos e atitudes:

- reconhecer a importância da orientação do potencial risco da gestação para mulheres portadoras de cardiopatias;

- participar junto com obstetras na avaliação das pacientes, no diagnóstico das cardiopatias e na identificação das pacientes de maior risco;
- reconhecer a importância da orientação da paciente quanto aos sinais/sintomas de descompensação cardiovascular;

- orientar obstetras para a observação, detecção de sinais/ sintomas de doenças cardiovasculares e encaminhamento para avaliação especializada;

- cooperar com obstetras e anestesistas para planejar o parto (data, método, terapia com medicamento);

- alertar obstetras para o risco de descompensação cardíaca no período pós-parto imediato;

- cooperar com ginecologistas e obstetras com relação às recomendações para contracepção.

\section{Doença cardíaca valvar}

A - Objetivos:

- ser capaz de realizar uma avaliação e tratamento adequado de pacientes com as patologias valvares;

- realizar seguimento clínico dos pacientes após cirurgia valvar ou intervenção percutânea, incluindo avaliação pósoperatória imediata e a longo prazo dos pacientes com prótese valvar.

B - Conhecimentos necessários:

- etiologia, imunologia, patogenia, grupos de risco, manifestações clínicas, evolução clínica, critérios diagnósticos, diagnóstico diferencial, tratamento e profilaxia (primária, secundária e terciária) da febre reumática;

- fisiopatologia das lesões valvares;

- limitações do exame ecocardiográfico e a necessidade de realização de outras técnicas diagnósticas nos casos de achados discrepantes;

- indicações, benefícios e riscos do tratamento clínico, cirúrgico e percutâneo;

- indicações e abordagem da anticoagulação;

- reconhecer o papel da doença cardíaca coronariana concomitante à doença valvar e o impacto do tratamento cirúrgico;

- ter conhecimento sobre a abordagem dos pacientes no pós-operatório imediato e a longo prazo. Manejo de diuréticos, anticoagulantes e outras medicamentos, profilaxia para endocardite infecciosa, abordagem da paciente valvopata gestante e do paciente em avaliação pré-operatória para cirurgia não cardíaca.

C - Habilidades:

- selecionar e indicar corretamente a realização de exames de imagem invasivos e não invasivos;

- interpretar os resultados dos exames diagnósticos;

- diagnosticar e tratar adequadamente os surtos de febre reumática;

- decidir sobre indicação cirúrgica no tempo adequado;

- orientar pacientes com relação à profilaxia de endocardite infecciosa;

- orientar profilaxia de febre reumática;

- reconhecer e abordar as complicações que podem ocorrer em pacientes com próteses valvares. 
D - Comportamentos e atitudes:

- cooperar com cirurgiões, hemodinamicistas, anestesistas e radiologistas na abordagem diagnóstica e terapêutica desses pacientes;

- reconhecer a importância da orientação do paciente com relação à história natural da doença valvar, abordagem da anticoagulação, profilaxia da febre reumática, da endocardite infecciosa e escolha da prótese valvar;

- informar ao paciente a necessidade da monitoração dos sintomas e visitas regulares ao cardiologista e acompanhamento no pós-operatório.

\section{Endocardite infecciosa}

\section{A - Objetivos:}

- avaliar, diagnosticar e tratar pacientes com endocardite infecciosa (El) de valva nativa e materiais protéticos.

B - Conhecimentos necessários:

- epidemiologia, patologia, patogênese e microbiologia da El;

- avaliação laboratorial e de imagem;

- descrever importância do ecocardiograma transesofágico;

- conhecer o tratamento antimicrobiano adequado para cada caso;

- indicações cirúrgicas no paciente com El;

- abordagem das complicações;

- reconhecer pacientes de alto risco;

- conhecer as indicações de profilaxia.

C - Habilidades:

- selecionar e indicar corretamente os métodos complementares necessários;

- selecionar o regime antimicrobiano adequado;

- ser capaz de determinar a necessidade e o tempo da indicação cirúrgica;

- abordar as complicações;

- prescrever antibioticoterapia profilática quando necessário.

D - Comportamentos e atitudes:

- quando necessário, desenvolver uma abordagem multidisciplinar com cirurgiões cardíacos e infectologistas para diagnóstico e abordagem dos pacientes;

- reconhecer a importância da orientação do paciente com relação à profilaxia.

\section{Febre reumática}

\section{A - Objetivos:}

- capacitação em diagnosticar, tratar e prevenir febre reumática e cardite reumática.

B - Conhecimentos gerais:

- etiopatogenia da febre reumática - sua relação com estreptococos beta-hemolítico;

- aspectos anatomopatológicos do envolvimento de estruturas cardíacas: valva mitral, demais valvas, endocárdio não valvar, miocárdio e pericárdio;
- dados epidemiológicos da doença;

- critérios de Jones modificados;

- novos métodos de auxílio diagnóstico: ecocardiografia, medicina nuclear;

- tratamento do estreptococos, uso de anti-inflamatórios e corticoides, eventual pulsoterapia;

- cirurgia em fase aguda;

- profilaxia primária e secundária.

C - Habilidades:

- interpretação dos exames bacteriológicos, de fase aguda de soro e sorológicos;

- diagnosticar por critérios;

- considerar dificuldades diagnósticas em reativação da doença;

- tratamento adequado;

- orientação familiar.

D - Comportamento e atitudes:

- saber enfatizar a importância da profilaxia da febre reumática.

\section{Insuficiência cardíaca}

\section{A - Objetivos:}

- conhecer o impacto da insuficiência cardíaca (IC) na morbimortalidade da população local;

- reconhecer as diferentes etiologias da IC;

- avaliação e tratamento dos pacientes com IC.

B - Conhecimentos necessários:

- epidemiologia, fisiopatologia e prognóstico da IC;

- reconhecer as complicações da IC (arritmias, risco de morte súbita, embolia, etc.);

- causas de descompensação e internação do paciente com IC;

- classificações internacionais de classe funcional;

- abordagem diagnóstica do paciente com IC suspeita ou conhecida: radiografia de tórax, peptídeos natriuréticos, ecocardiograma, ECG, Holter, teste de estresse, cateterismo cardíaco;

- descrever abordagem clínica do paciente com IC aguda e crônica;

- indicações de cardiodesfibriladores, ressincronizadores e marca-passos;

- descrever o papel da cirurgia, incluindo transplante;

- identificar o papel de programas de reabilitação cardíaca;

- reconhecer a importância de equipe multidisciplinar no atendimento ao paciente;

- identificar as complicações dos pacientes com IC;

- determinar a abordagem clínica de seguimento desses pacientes;

- conhecer indicações e contraindicações ao transplante cardíaco;

- determinar o seguimento apropriado de pacientes após transplante cardíaco. 


\section{C - Habilidades:}

- selecionar e indicar adequadamente técnicas diagnósticas para as várias etiologias de IC;

- prescrever terapia farmacológica e não farmacológica adequada e realizar acompanhamento a longo prazo e reajustes da terapêutica, sempre que necessário;

- estratificar o risco do paciente e avaliar indicação de ressincronizadores, cardiodesfibriladores, marca-passos e cirurgia (incluindo transplante).

D - Comportamentos e atitudes:

- enfatizar a importância da perda de peso, mudanças no estilo de vida, exercícios. Ajudar na compreensão da necessidade do uso de múltiplos medicamentos;

- considerar a importância dos programas de reabilitação;

- reconhecer as vantagens e limitações das terapias específicas;

- orientar importância da aderência ao tratamento, verificar motivos para não aderência;

- reconhecer importância do cuidado suportivo, paliativo nos pacientes com IC grave, sem indicação de abordagem específica.

\section{Hipertensão arterial pulmonar}

A - Objetivos:

- diagnosticar hipertensão arterial pulmonar (HAP);

- proporcionar abordagem ótima aos pacientes com HAP;

- distinguir as diferentes causas de HAP.

B - Conhecimentos necessários:

- definir HAP e sua classificação funcional;

- incidência, prevalência, etiologia, grupos de alto risco;

- fisiopatologia da HAP;

- características clínicas da HAP;

- critérios diagnósticos para HAP;

- identificar marcadores prognósticos;

- abordagem da HAP: clínica, cirúrgica e intervencionista.

C - Habilidades:

- reconhecer sinais clínicos sugestivos de HAP;

- saber indicar e interpretar os exames complementares: gasometria arterial, marcadores cardíacos, teste de função pulmonar, ECG, ecocardiograma, teste de estresse cardiopulmonar, cintilografia de ventilação e perfusão, TC, RNM, cateterismo cardíaco, angiografia pulmonar, biopsia pulmonar;

- indicar tratamento clínico ou cirúrgico de acordo com cada avaliação individual;

- avaliar marcadores clínicos e hemodinâmicos de prognóstico.

D - Comportamentos e atitudes:

- cooperar com outros médicos generalistas e especialistas para reconhecimento da hipertensão pulmonar;

- cooperar com especialistas (médico assistente, cirurgiões torácicos e cardíacos, radiologistas, hemodinamicistas) para o diagnóstico diferencial e tratamento cirúrgico, quando indicado;

- proporcionar aconselhamento genético para famílias afetadas por HAP primária;

- orientar e proporcionar condições para que o paciente seja aderente ao tratamento;

- estar alerta para a prevalência aumentada de HAP em determinadas condições, como por exemplo, a esclerodermia;

- encaminhar paciente para especialista, quando necessário.

\section{Reabilitação e fisiologia do exercício}

\section{A - Objetivos:}

- ser capaz de proporcionar reabilitação apropriada e serviços de prevenção secundária para pacientes com doenças cardiovasculares, especialmente síndromes coronarianas agudas, após revascularização do miocárdio, angina estável, pacientes de alto risco cardiovascular, insuficiência cardíaca, diabetes e outros;

- avaliar o risco cardiovascular e a capacidade de exercício dos pacientes;

- avaliar as características do coração do atleta.

B - Conhecimentos necessários:

- definir reabilitação e prevenção secundária como componentes integrados dos cuidados do paciente com doença cardiovascular;

- definir estratificação de risco e populações-alvo;

- compreender a avaliação de base do paciente, teste de exercícios, treino de exercícios, educação do paciente, intervenção no estilo de vida, abordagem dos fatores de risco, suporte psicossocial;

- compreender a fisiologia do esporte, dos exercícios e os benefícios do treino de exercício;

- reconhecer aspectos fisiológicos da reabilitação;

- descrever programas para populações específicas em contextos apropriados.

C - Habilidades:

- realizar e interpretar estratificação de risco usando teste de exercício, ecocardiograma e outros exames, quando indicado;

- prescrever programas de exercício, especificando modalidade, intensidade, duração e progressão e outras intervenções no estilo de vida;

- prescrever medicações conforme indicações das diretrizes;

- reconhecer características do coração de atleta: ECG, ecocardiograma.

D - Comportamentos e atitudes:

- reconhecer a reabilitação e a prevenção secundária como um componente integrado do cuidado cardiovascular;

- reconhecer a importância da reabilitação e prevenção secundária na vida pessoal, profissional e social dos pacientes com doença cardíaca; 
- reconhecer a importância da educação do paciente e seus familiares;

- reconhecer a importância de outros profissionais, incluindo enfermeiros, fisioterapeutas, psicólogos, nutricionistas;

- reconhecer o papel dos esportes na Cardiologia.

\section{Arritmias}

A - Objetivos:

- ser capaz de avaliar e tratar os pacientes com arritmias;

- eletrofisiologia: ter boa compreensão do diagnóstico e tratamento das arritmias, saber solicitar e interpretar os resultados básicos do exame, tais como medidas de intervalos $\mathrm{AH}$ e $\mathrm{HV}$, inducibilidade de arritmias, assim como ter conhecimento das principais complicações;

- conhecer o funcionamento básico dos dispositivos cardíacos implantáveis (marca-passos, desfibriladores e ressincronizadores), suas indicações e complicações, além de ter noções sobre a programação e o acompanhamento desses dispositivos;

- ser capaz de passar um marca-passo provisório à beira do leito;

- cardiodesfibrilador implantável (CDI): ser capaz de avaliar pacientes para indicação de CDI.

B - Conhecimentos necessários:

- classificar e definir: bradicardias, taquicardias (arritmias ventriculares e supraventriculares);

- epidemiologia, fisiopatologia, genética, diagnóstico e características clínicas das arritmias;

- realizar avaliação de risco, avaliação prognóstica;

- princípios de eletrocardiografia e eletrofisiologia e achados relevantes das diferentes arritmias, incluindo características de alto risco no ECG de repouso, tais como QT longo, QT curto e síndrome de Brugada;

- farmacologia dos medicamentos antiarrítmicos;

- princípios da abordagem invasiva das arritmias: ablação por cateter, estimulação artificial (marca-passo temporário e definitivo), implante de CDI e tratamento cirúrgico.

C - Habilidades:

- abordagem aguda das arritmias com manobras vagais, medicamentos e cardioversão elétrica;

- prescrever terapia para prevenção de recorrência das arritmias;

- realizar monitoração eletrocardiográfica e saber interpretá-la;

- interpretar estudo eletrofisiológico;

- quando apropriado, encaminhar pacientes para ablação por cateter e realizar acompanhamento clínico posteriormente;

- indicar terapia com CDI, ressincronizador e marca-passo, quando apropriado;

- realizar implante de marca-passo provisório;

- realizar seguimento de pacientes em uso de marca-passo (programação, interrogação);

D - Comportamentos e atitudes:

- compreender a ansiedade do paciente que sofre algum tipo de arritmia cardíaca e que é submetido à métodos invasivos diagnósticos e terapêuticos;

- considerar a importância de doenças estruturais cardíacas coexistentes, incluindo DAC, em relação aos resultados e abordagens das arritmias;

- considerar as limitações e potenciais riscos da terapia antiarrítmica;

- compreender os problemas médicos e psicossociais que afligem o paciente com IC terminal e ativações frequentes (aplicação de choque) do CDI.

\section{Fibrilação atrial}

\section{A - Objetivos:}

- ser capaz de realizar avaliação e tratamento de pacientes com fibrilação atrial (FA).

B - Conhecimentos necessários:

- descrever a epidemiologia, prognóstico e fisiopatologia da FA;

- classificar a FA;

- descrever o diagnóstico, características clínicas e impacto na qualidade de vida do paciente;

- identificar condições associadas;

- descrever complicações embólicas;

- descrever a abordagem de:

- terapia anticoagulante;

- controle de ritmo x controle de frequência;

- prevenção de recorrência;

- terapia com marca-passo;

- ablação por cateter;

- cirurgia.

C - Habilidades:

- realizar anticoagulação adequada, estratificar risco embólico e hemorrágico utilizando escores validados;

- selecionar adequadamente pacientes para cardioversão, realizar cardioversão química e elétrica;

- prescrever terapia farmacológica para controle de ritmo;

- prescrever terapia farmacológica para controle de frequência;

- quando necessário, encaminhar para: estudo eletrofisiológico, ablação por cateter, ablação cirúrgica, implante de marca-passo, ablação da junção AV e marcapasso.

D - Comportamentos e atitudes:

- compreender a ansiedade do paciente com diagnóstico de arritmia e necessidade (em alguns casos) de realizar exames invasivos;

- reconhecer a importância das doenças cardíacas estruturais no resultado e na abordagem da FA;

- considerar as limitações e potenciais riscos da terapia antiarrítmica;

- considerar a importância da terapia anticoagulante;

- encaminhar pacientes para especialistas em procedimentos percutâneos ou ablação cirúrgica, quando necessário. 


\section{Síncope}

\section{A - Objetivos:}

- definir síncope;

- diferenciar síncope de outras causas de perda da consciência;

- avaliar e tratar pacientes com síncope.

B - Conhecimentos necessários:

- epidemiologia, fisiopatologia e a prevalência de diferentes causa de síncope;

- classificar as causas de síncope (ex: neuromediada, Stokes Adams, hipotensão ortostática)

- definir o prognóstico;

- avaliação diagnóstica: anamnese, exame físico, ECG ecocardiograma, teste de exercícios, teste de inclinação (Tilt test), Holter, Loop e estudo eletrofisiológico;

- tratamento das diferentes condições: síncope neuromediada, hipotensão ortostática, arritmias cardíacas, doença cardíaca estrutural e doença cardiopulmonar.

C - Habilidades:

- interpretar: ECG, ecocardiograma, massagem do seio carotídeo, teste da inclinação (Tilt test), Holter, Loop, monitor de eventos externo e implantável, estudo eletrofisiológico, teste de exercícios, cateterismo cardíaco e angiografia de coronárias;

- realizar estratificação de risco;

- selecionar tratamento adequado: orientações, manobras físicas, terapia com medicamentos, implante de dispositivos (CDI, marca-passo).

D - Comportamentos e atitudes:

- considerar o impacto da síncope no estilo de vida dos pacientes;

- solicitar a opinião de outros especialistas, quando necessário;

- reconhecer quando o paciente com síncope deve ser hospitalizado;

- considerar que o diagnóstico de síncope é frequentemente presumido;

- considerar as limitações dos exames complementares para o diagnóstico etiológico;

- reconhecer que a maioria dos pacientes não necessita de nenhum tratamento específico;

- considerar a relação risco-benefício e custo-eficácia dos métodos terapêuticos: marca-passo, CDI e ablação por cateter.

\section{Morte súbita e ressuscitação}

\section{A - Objetivos:}

- abordar (estratificação de risco, investigação, tratamento) pacientes com risco de morte súbita ou recuperados de morte súbita;

- ser capaz de realizar suporte de vida básico e avançado.

B - Conhecimentos necessários:

- definir morte súbita e conhecer a epidemiologia, etiologia, fisiopatologia e apresentação clínica das diferentes condições que podem levar à morte súbita;

- definir a abordagem aguda de pacientes com parada cardíaca;

- ressuscitação cardiopulmonar em situações especiais, por exemplo, gestantes, crianças e hipotermia;

- definir a avaliação diagnóstica e estratificação de risco dos sobreviventes, especialmente reconhecer sinais eletrocardiográficos indicativos de risco de morte súbita (QT longo, QT curto, síndrome de Brugada, etc.), saber como realizar avaliação adicional desses pacientes e suas famílias;

- selecionar abordagem terapêutica a longo prazo adequada;

- conhecer as recomendações atuais para prevenção primária e secundária de morte súbita (ex: implante de CDI);

- identificar, estratificar risco e abordar pacientes com risco elevado de morte súbita, incluindo membros das famílias desses pacientes.

C - Habilidades:

- realizar ressuscitação cardiorrespiratória;

- identificar causas de parada cardiorrespiratória (PCR);

- coordenar ações e aplicar conhecimentos do suporte avançado de vida;

- interpretar pródromos, causas subjacentes e prognóstico de sobreviventes de morte súbita;

- capacidade de liderança no atendimento da PCR;

- interpretar a estratificação de risco usando métodos complementares;

- realizar seguimento ambulatorial de pacientes recuperados de morte súbita.

D - Comportamentos e atitudes:

- reconhecer a importância da urgência do atendimento da PCR;

- reconhecer a importância dos pródromos;

- compreender a ansiedade do paciente e sua família;

- considerar a importância da orientação do paciente e prevenção secundária;

- considerar a importância de um trabalho coordenado de equipe durante o atendimento de PCR.

\section{Doenças da aorta e trauma da aorta e coração}

A - Objetivos:

- avaliar pacientes com doenças da aorta e trauma da aorta e do coração;

- programar o tratamento clínico, intervencionista ou cirúrgico apropriado.

B - Conhecimentos necessários:

- epidemiologia, etiologia, patologia, genética, fisiopatologia e apresentação clínica das doenças da aorta e trauma da aorta e coração: dissecção de aorta e síndrome aórtica aguda, hematoma intramural, transecção aórtica traumática, dissecção crônica da aorta, aneurisma da aorta torácica, doença ateromatosa da aorta, aortite e trauma do coração; 
- limitações dos diferentes exames de imagem;

- descrever abordagem clínica, intervencionista e cirúrgica.

C - Habilidades:

- escolher, realizar e interpretar os exames de imagem apropriados (ecocardiograma transtorácico e transesofágico, RNM, TC, ultrassom de superfície e endovascular, angiografia da aorta e do coração);

- abordar as diferentes doenças da aorta com a modalidade de tratamento mais rápida e adequada.

D - Comportamentos e atitudes:

- cooperar com cirurgiões cardiovasculares, cardiologistas intervencionistas e radiologistas para o diagnóstico e tratamento;

- reconhecer a necessidade da urgência na abordagem dos pacientes com doenças da aorta e trauma cardíaco;

- realizar triagem familiar nos casos indicados;

- realizar seguimento ambulatorial a longo prazo dos pacientes com doença da aorta.

\section{Doença arterial periférica}

A - Objetivos:

- ser capaz de avaliar e tratar pacientes com doença arterial periférica (DAP).

B - Conhecimentos necessários:

- descrever epidemiologia e patologia da DAP;

- descrever diagnóstico e avaliação;

- descrever terapêutica clínica e cirúrgica (percutânea e cirúrgica);

- definir prognóstico;

- lembrar a associação da DAP com doença vascular em outros territórios (coronárias, carótidas e artérias renais);

- conhecer as causas de isquemia aguda de membros, de outras urgências e suas respectivas abordagens.

C - Habilidades:

- realizar especialmente exame dos pulsos periféricos;

- identificar os fatores de risco e selecionar a melhor estratégia de abordagem, lembrando que a DAP é uma manifestação de aterosclerose generalizada;

- selecionar, usar e interpretar os métodos diagnósticos adequadamente: dúplex scan (e outras modalidades de Doppler, incluindo avaliação do índice tornozelo-braquial), angiorressonância, angiotomografia, angiografia.

D - Comportamentos e atitudes:

- considerar a natureza sistêmica da aterosclerose e suas implicações para o paciente com doença manifesta em um dado território;

- reconhecer a importância da modificação dos fatores de risco na prevenção;

- ajudar os pacientes a adotarem um estilo de vida saudável;

- colaborar com especialistas (cardiologistas intervencionistas, radiologistas, cirurgiões vasculares e endocrinologistas) na abordagem desses pacientes.
34. Doença venosa tromboembólica

\section{A - Objetivos:}

- ser capaz de diagnosticar, tratar e prevenir a trombose venosa profunda (TVP) e tromboembolismo pulmonar (TEP).

B - Conhecimentos necessários:

- epidemiologia e os fatores de risco para TVP;

- explicar a elevação da resistência vascular pulmonar e os defeitos de perfusão pulmonar;

- apresentação clínica da TVP e do TEP;

- complicações cardíacas (cor pulmonale);

- avaliação diagnóstica, importância e limitações de cada método: biomarcadores (D-dímero e troponina), ECG, ecocardiograma, ultrassom com Doppler de membros inferiores e veias da pelve, cintilografia de ventilação e perfusão pulmonar, angiotomografia, angiorressonância e angiografia pulmonar;

- tratamento: heparinas, antagonistas da vitamina K, novos anticoagulantes, trombólise e embolectomia;

- indicação das medidas de prevenção: meias de compressão, heparinas;

- abordagem da hipertensão arterial pulmonar crônica, incluindo tromboendarterectomia.

C - Habilidades:

- interpretar ECG, ecocardiograma, angiotomografia e cintilografia pulmonar;

- selecionar a terapia apropriada a cada caso;

- diagnosticar e tratar TVP;

- definir duração da terapia de anticoagulação de acordo com o contexto clínico.

D - Comportamentos e atitudes:

- considerar a dificuldade diagnóstica da TVP e TEP baseando-se apenas nos achados clínicos;

- colaborar com outros especialistas, incluindo radiologistas e médicos nucleares;

- orientar o paciente da importância da aderência à terapia anticoagulante, e informar sobre riscos do controle inadequado da anticoagulação.

\section{Doenças cardiovasculares no paciente idoso}

\section{A - Objetivos:}

- reconhecer as diferenças existentes na avaliação, tratamento e seguimento de pacientes idosos portadores de cardiopatia;

- reconhecer as principais modificações estruturais, funcionais e hemodinâmicas relacionadas ao envelhecimento do sistema cardiovascular.

B - Conhecimentos necessários:

- conceitos e fundamentos do estudo do envelhecimento;

- fisiologia do envelhecimento cardiovascular;

- epidemiologia e sociologia do envelhecimento;

- avaliação da qualidade de vida na velhice;

- grandes síndromes geriátricas: iatrogenia, insuficiência cerebral (cognição e demências), instabilidade postural, imobilidade e incontinência; 
- alterações farmacodinâmicas e a farmacocinéticas na população idosa;

- particularidades das grandes síndromes cardiológicas aplicadas à população idosa.

C - Habilidades:

- realizar anamnese e exame clínico adequados aos pacientes idosos;

- estratificar o risco cardiovascular em pacientes idosos;

- indicar e interpretar a propedêutica cardiovascular especializada em pacientes idosos, reconhecendo suas particularidades;

- indicar e realizar acompanhamento clínico de pacientes idosos portadores de cardiopatia;

- indicar o tratamento intervencionista em pacientes idosos portadores de cardiopatia;

- compreender as ações da equipe multidisciplinar envolvida no tratamento de pacientes idosos portadores de cardiopatia;

- orientar e compreender a relação da família e dos cuidadores durante a abordagem do paciente idoso portador de cardiopatia;

- estabelecer as prioridades terapêuticas no paciente idoso portador de múltiplas patologias.

D - Comportamentos e atitudes:

- relacionar, compreender e orientar, de forma humanizada, os pacientes idosos, seus familiares e cuidadores;

- orientar geriatras, gerontólogos e equipe multidisciplinar a respeito das características das cardiopatias e principais sinais/sintomas indicativos de agravo à saúde do paciente idoso portador de cardiopatia;

- valorizar, no momento de decisões terapêuticas, a funcionalidade e qualidade de vida no paciente idoso portador de cardiopatia;

- valorizar o idoso e impedir sua discriminação, respeitando e fazendo-se respeitar o Estatuto do Idoso;

- orientar a equipe de saúde e familiares em relação às normas previstas no Código de Ética Médica a respeito da finitude: eutanásia, distanásia e ortotanásia.

\section{Cirurgia}

A - Objetivos:

- seleção dos pacientes, indicação dos procedimentos;

- cuidados no pré e pós-operatório;

- ajuda na tomada de decisões na indicação de procedimentos cirúrgicos, fazendo parte da equipe como um todo.

B - Conhecimentos necessários:

- conhecer e saber orientar-se pelas diretrizes das entidades médicas, reconhecendo as limitações e exceções de sua utilização, adaptando-as à sua realidade;

- indicações e contraindicações dos procedimentos cirúrgicos considerados como padrão-ouro para o tratamento das cardiopatias de maior incidência epidemiológica na população;
- estimar o risco de uma intervenção utilizando os escores de risco e conhecer as probabilidades de sucesso para um dado paciente;

- saber pesar riscos e benefícios do tratamento baseado em análise da qualidade de evidência e dominar técnicas de controle da redução absoluta de risco;

- conhecer as vantagens e desvantagens de diferentes opções terapêuticas para uma mesma afecção;

- assistir e esclarecer os pacientes quando da obtenção do consentimento informado na tomada de decisões baseadas em evidências, respeitando as preferências individuais dos pacientes;

- conhecer as condutas expostas em protocolos assistenciais relativas ao preparo pré-operatório das diversas intervenções cirúrgicas, tanto em caráter eletivo quanto de urgência ou emergência.

C - Habilidades, comportamentos e atitudes:

- reconhecer sintomas e sinais clínicos de descompensação cardiocirculatória e de comprometimento dos outros subsistemas orgânicos capazes de aumentar o risco de morte e complicações peri e pós-operatórias;

No pré-operatório:

- saber selecionar os exames laboratoriais auxiliares capazes de avaliar o grau de dano funcional existente, auxiliando a planejar as medidas de recuperação de função considerando a relação custo-benefício;

- conhecer e saber instituir medidas terapêuticas capazes de controlar ou diminuir a descompensação dos subsistemas orgânicos com a finalidade de reduzir os riscos da intervenção e melhorar o prognóstico no pós-operatório;

- produzir um relatório sucinto descrevendo o diagnóstico, medidas de preparo pré-operatório e compensação das funções fisiológicas dos subsistemas, medicamentos em uso ou suspensos, recomendações de monitoração e cálculo de risco operatório para orientar anestesistas e cirurgiões;

- reunir-se com o paciente e com membros da família com a finalidade de explicar as decisões finais e o prognóstico imediato no sentido de diminuir o estresse e encorajar uma atitude positiva em relação à cirurgia.

No acompanhamento perioperatório:

- saber indicar o monitoramento das funções fisiológicas principais e complementares e recomendar medidas especiais de proteção de órgãos, de acordo com o grau de acometimento dos subsistemas detectados no pré-operatório, no sentido de minimizar danos;

- estar apto, quando solicitado a interpretar e tratar arritmias, insuficiência cardíaca, distúrbios metabólicos e eletrolíticos ou efeitos deletérios da associação de medicamentos utilizados no pré-operatório com os medicamentos anestésicos;

- saber indicar assistência circulatória mecânica nos casos de síndrome de baixo débito pós-perfusão não responsivos à terapêutica farmacológica, ou de reposição de volume em síndromes de choque hipovolêmico ou vasoplégico; 
- exposição por acompanhamento, no centro cirúrgico, a no mínimo três cirurgias cardiovasculares de revascularização do miocárdio, plastia e troca valvar, correção de aneurismas e ou dissecção da aorta torácica, implante de marca-passos e cardioversores desfibriladores e correção de cardiopatias congênitas.

No acompanhamento do pós-operatório imediato:

- saber realizar o exame inicial de chegada na CTI do paciente operado e descrever os achados clínicos dos principais subsistemas em relatório sucinto sistematizado;

- saber solicitar um conjunto de exames laboratoriais de avaliação do estado funcional do paciente, interpretando os possíveis desvios da normalidade e sabendo indicar as medidas corretivas;

- diagnosticar as complicações de alto potencial de mortalidade, tais como: síndromes hemorrágicas e choque hipovolêmico, tamponamento cardíaco, síndrome de baixo débito, arritmias graves, insuficiência respiratória aguda e insuficiência renal, sabendo indicar o tratamento adequado;

- ser capaz de instalar equipamentos de suporte ventilatório, hemodinâmico e de monitoramento cardiovascular, e de realizar cateterização percutânea de veias e artérias para colocação de cateteres ou coleta de exames, além de introduzir eletrodos transitórios intracavitários para estimulação cardíaca;

- conhecer os critérios de alta da CTI e descrever um relatório sucinto de alta desta unidade.

Acompanhamento do pós-operatório hospitalar e em longo prazo:

- realizar exame clínico diário, sendo capaz de identificar os sinais de evolução desfavorável, tais como: atelectasia ou pneumonia, derrame pleural, infecção e/ou deiscência da ferida operatória, arritmias e insuficiência cardíaca, endocardite infecciosa e sopros de disfunção de valvas ou próteses, isquemia por obstrução precoce de enxertos, propondo uma estratégia de investigação e tratamento;

- realizar, na alta ou na primeira consulta, exame clínico e laboratorial que servirão de base de comparações nos exames futuros para estimar a evolução e o prognóstico do paciente em longo prazo;

- saber orientar o paciente quanto à necessidade de aderência aos medicamentos, ao controle de fatores de risco favorecedores de obstrução dos enxertos, à profilaxia de infecções, de trombose e de tromboembolismo nos portadores de próteses e de outros dispositivos implantados;

- ser capaz de instruir o paciente quanto ao aparecimento de sintomas e sinais de alarme de funcionamento inadequado de próteses valvares e dispositivos para tratamento de arritmias e do retorno de síndromes isquêmicas;

- propor e executar com base em protocolos clínicos de seguimento tardio um esquema de revisão periódica adequado a cada tipo de intervenção, como o controle nos pacientes em uso crônico de anticoagulantes portadores de próteses valvares, e/ou de fibrilação atrial crônica, e na detecção de sinais precoces de desgaste de fonte de energia nos portadores de dispositivos antiarrítmicos;

- ser solidário com o paciente que apresenta complicações, ficando ao seu dispor para orientá-lo nas decisões necessárias, assumindo a responsabilidade de encaminhá-lo a um centro médico com capacidade resolutiva, demonstrando empatia e comprometimento profissional;

- saber diagnosticar complicações tardias ou a presença de novas enfermidades cardiovasculares, que impliquem na necessidade de reoperação, tais como: lesões em outras valvas ou em outras artérias, sabendo oferecer a melhor conduta baseada nas evidências médicas.

\section{Referências}

1. Ministério da Saúde. Datasus. Caderno de informações de saúde. Brasília; 2009.

2. Movahed MR, John J, Hashemzadeh M, Jamal MM, Hashemzadeh M. Trends in the age adjusted mortality from acute ST segment elevation myocardial infarction in the United States (1988-2004) based on race, gender, infarct location and comorbidities. Am J Cardiol. 2009;104(8):1030-4

3. Daniel E, Germiniani H, Nazareno ER, Braga SV, Winkler AM, Cunha CL. Tendência da mortalidade por doenças isquêmicas do coração na cidade de Curitiba - Brasil, de 1980 a 1998. Arq Bras Cardiol. 2005;85(2):100-4.

4. Goldman L, Ausiello D, eds. Cecil Medicine. Philadelphia: Saunders Elsevier; 2008. Chap. 1

5. Maia JA. O ensino de cardiologia na graduação médica: desafios atuais. Arq Bras Cardiol. 2004;82(3):302-6.

6. Epstein RM. Assessment in medical education. N Engl J Med. 2007;356(4):387-96
7. Ministério da Saúde. Conselho Federal de Medicina. Resolução CFM 1845/2008. Diário Oficial da União, Brasília, 2008 jul 15; Seção I, p. 72.

8. Ministério da Saúde. Conselho Federal de Medicina. Pós Graduação não tem valor de especialização, reitera plenário do CFM. 2010 [acesso em 2010 julho 13]. Disponível em http://www.isaude.net/pt_br/noticia/

9. Luna Fo B, Lima VC, Ferreira Fo C, Gun C, Campos Fo O, Póvoa R, et al Anteprojeto de residência médica em cardiologia. Comissão de Estágio e Residência Médica em Cardiologia SBC/FUNCOR. Arq Bras Cardiol. 1999;72(3):393-5.

10. European Society of Cardiology; Kearney P, Tay Ergene A, Escaned J, Flachskmp F, Griebenow R, Kristesen S, et al. Core curriculum for the general cardiologist. Education Committee of the European Society of Cardiology. France; 2008.

11. ACCF 2008 Recommendations for Training in Adult Cardiovascular Medicine Core Cardiology Training (COCATS 3) (revision of the 2002 COCATS Training Statement); Beller GA, Bonow RO, Fuster V, ACC Foundation, AHA; ACP Task Force on Clinical Competence and Training. J Am Coll Cardiol. 2008;51(3):335-8. 


\section{Diretrizes}

12. Ministério da Educação e Cultura. Conselho Nacional de Educação Câmara de Educação Superior. Resolução CNE/CES no 4, de 7 de novembro de 2001: institui Diretrizes Curriculares Nacionais do Curso de Graduação em Medicina. [acesso em 2010 jul 20]. Disponível em: http://portal.mec.gov.br/cne/arquivos/pdf/CESO4.pdf

13. Hafferty FW. Professionalism: the next wave. N Engl J Med. 2006;355(20):2151-2.

14. Sheikh A. Dealing with ethics in a multicultural world: willingness to appreciate less familiar views and traditions in crucial. West J Med. 174(2):87-8.
15. Lorenz KA, Lynn J, Dy SM, Hugarman LR, Wilkinson A, Mularski RA, et al. Evidence for improving palliative care at the end of life: a systematic review. Ann Intern Med. 2008;148(2):147-59.

16. Aronow WS, Frishman WH, Cheng-Lai A. Cardiovascular drug therapy in the elderly. Cardiol Rev. 2007;15(4):195-215.

17. Ministério da Saúde. Estatuto do Idoso. Lei Federal n ${ }^{\circ} 10741$ de $1^{\circ}$ de outubro de 2003. [acesso em 2010 jul 20]. Disponível em http://www. assistenciasocial.al.gov.br/legislacao/legislacao-federal/est. \%20de\%20 idoso.pdf 



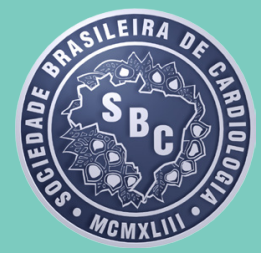

Sociedade Brasileira de Cardiologia www.cardiol.br 